\title{
Research Status and Environmental Protection Disposal of Recycled Electrolytic Manganese Residue
}

\author{
Ke Liu (D1147319057@qq.com ) \\ Chongqing Jiaotong University https://orcid.org/0000-0002-1144-9896 \\ Chao-qiang Wang
}

Chongqing Jiaotong University

De-ming Huang

Chongqing Jiaotong University

Qi-cong Huang

Chongqing Institute of Modern Construction Industry Development

Pei-xin Wang

CSCEC Science \& Technology(Fuzhou)

\section{Xu-dong Mei}

Chongqing Environment Protection Engineering Technology Center for Shale Gas Development

\section{Yu Chen}

Chongqing haopan energy saving technology

\section{Shu-chun Li}

Chongqing shang jia electronics limited liability company

\section{Kai Wu}

Tongji University

\section{Research Article}

Keywords: EMR, Utilization, Sintered brick, Environment-friendly

Posted Date: November 11th, 2021

DOI: https://doi.org/10.21203/rs.3.rs-1025026/v1

License: (c) (i) This work is licensed under a Creative Commons Attribution 4.0 International License.

Read Full License 


\section{Abstract}

Electrolytic manganese residue (EMR) is a common industrial solid waste. The ammonia and manganese components contained in it will pollute the soil environment and have potential risks to human health. Under the premise of investigating the production of electrolytic manganese slag and conventional processes, it is found that the traditional harmless treatment methods of electrolytic manganese slag are still mainly lime solidification, cement solidification, and fly ash solidification, and the resource utilization directions such as cement, concrete, non-sintered bricks, road bases, etc. are mainly used. But, EMR contains ammonia nitrogen, and manganese (prone to leaching) that difficult to meeting environmental protection requirements by using general cement cementitious material solidification. Therefore, this study focused on manufacturing new eco-friendly bricks with EMR using calcination process. Specifically, the physical performance and environmental characterization of the sintered bricks were investigated. Furthermore, the sintering behavior and crystallization of all bricks containing EMR were studied using XRD, FT-IR, and SEM. The results showed the EMR leaching solution contained $1256 \mathrm{mg} / \mathrm{L}$ and 8120 $\mathrm{mg} / \mathrm{L}$ of ammonia nitrogen and manganese, respectively, both of them exceeds Chinese standards (GB 8978-1996). Because of EMR is rich in $\mathrm{Fe}_{2} \mathrm{O}_{3}$ and $\mathrm{K}_{2} \mathrm{O}$, it greatly promotes particle rearrangement and transfer in the EMR system, reducing the sintering temperature. The compressive strength, leaching performance and radioactivity of sintered bricks with EMR all met the state standard requirement for "sintered common bricks" (GB/T 5101-2017) and (GB 8978). The product can be used as bricks of MU20 grade of Chinese standard. The study provides an effective method for the safe and environmentally friendly disposal of EMR.

\section{Introduction}

Electrolytic manganese residue (EMR) generated from smelting wastes produced during the electrolytic production of manganese metal from manganese ore. China has abundant manganese resources and provides this metal worldwide, as well as manganese ore consumers. Producing one ton of manganese metal electrolytically generates between 5-9 tons of EMR. Annually millions tons of EMR wastes therefore generate from production via electrolysis or acid leaching. These levels reached 1.01 million tons in 2015 , of which 720,000 tons were produced from domestic manganese ores. Currently, the accumulated stock of EMR wastes are more and more high and occupying a significant landfill volume. This increases disposal costs for businesses and incurs potential safety hazards. Moreover, some harmful elements in EMR enter the environment via rainfall or dust(Zhou et al., 2014.Nan.et al, 2009, Silva et al, 2007., Wang et al, 2016). Therefore, the resource utilization of EMR has become an urgent need.

Historically, widely abundant clay reserves in China have served as an important construction material, especially for conventional sintered brick-marking. However, some limits on clay do exist, which include the location of reserves and political policies. For example, in order to save clay resources, the Chinese government began to prohibit its use in the brick industry in the early twenty-first century. Note that the EMR is also a type II industrial waste, rich in $\mathrm{Fe}_{2} \mathrm{O}_{3}$ and $\mathrm{K}_{2} \mathrm{O}$, which promotes particle rearrangement, transfer in the EMR system, and materials sintering. 
First of all, this article has done a literature survey on the harmless treatment methods and resource treatment methods of electrolytic manganese slag at home and abroad, and found that the comprehensive utilization of EMR has many directions, including concrete, non-sintered bricks, cement and sintered products(Feng et al, 2006;Li et al, 2007;Lan, 2006;Yang et al, 2014;Li ea al, 2014a;Xu et al, 2011; Han at al,2018; Hou et al, 2012; Wang et al, 2019;Tang et al, 2019). Studies have shown that manganese in EMR is easy to leach, and it also contains ammonia nitrogen components. The method of using cement cementitious materials to solidify characteristic pollutants is not effective. So, a systematic and harmless treatment method were used, and then proposed a new type of environmentally friendly brick with electrolytic manganese slag as the main raw material, and proved the practicability and safety of the product through experiments.

\section{Production And Disposal Of Emr}

\subsection{Source of EMR and its production process}

- Manganese is an important strategic resource, can be widely used in iron and steel industry, aviation, medicine and other industries. It is the basic raw material to support economic construction and industry development(Wang et al, 2020;Banerjee et al, 2017;Camargo et al, 2018). China's electrolytic manganese industry development is relatively late, but it develops rapidly and has been the largest producer, exporter and consumer of electrolytic manganese in the world(Zhou et al, 2020;Cong et al, 2018). In recent years, China is in a crucial period of mining upgrading and transformation, and the national environmental protection policy is becoming more and more strict. Thus, after 2015 China's manganese ore production showed a "cliff-breaking" decline, which is far from keeping up with the development of metallurgical industry, and the degree of external dependence continues to climb(Cong et al, 2018). At present, almost all electrolytic manganese in the world is produced in China and South Africa, and China's electrolytic manganese production accounts for more than $97 \%$ of the global production(Zhang et al, 2020). The electrolytic manganese production process in China has always been using the acid leaching electrolytic hydrometallurgy process proposed by the United States Bureau of mines in 1935(Brantley et al, 1968), and the raw material is mainly manganese ore (rhodochrosite or manganese oxide reduction ore)(Du et al, 2013). The following figure 1 is the process flow chart of electrolytic manganese production(He et al, 2021).

Although China's Electrolytic Manganese market is developing rapidly, compared with western developed countries, the overall technical level of the industry has the disadvantages of low product quality, low resource application efficiency and high production cost and so on.. In the process of electrolytic manganese production, a large amount of electrolytic manganese slag will be produced. Coupled with the impact of manganese ore taste and smelting process, the stock and yield of electrolytic manganese slag in China is huge, and its disposal has been in a relatively conservative state. Presently, it is still mainly transported to a dedicated site for damming and stacking ${ }^{[1]}$.Under the leaching action of natural rainfall, electrolytic manganese slag releases a large number of soluble manganese $\left(\mathrm{Mn}^{2+}\right)$, ammonia nitrogen 
$\left(\mathrm{NH}_{4}{ }^{+} \mathrm{N}\right)$ (Qian et al, 2012; Chen et al, 2015). Therefore, this treatment has a large environmental pollution hidden dangers and take up a quantity of land resources. It is urgent to find a reasonable and effective solution of electrolytic manganese slag.

\subsection{Disposal status of EMR}

\subsubsection{Curing/stabilization treatment}

The traditional harmless treatment of EMR can be divided into sorting processingt, curing treatment and so on(Shu et al, 2016;Lan et al, 2021). Sorting processing can sort out the qualified raw materials by using the different physical and chemical properties of EMR and then can be used to produce electrolytic manganese. Solidification treatment is the most primary way of harmless treatment of EMR, including lime curing, cement curing, fly ash curing, self-glue curing, etc(Vinter et al, 2016;Chuwi et al, 2012). By using cement and other solidification materials to fix the harmful elements such as heavy metals in EMR into inert basic materials, the slag can be used rationally.

Mu et al(2020) used composite portland cement (PC32.5R) as curing agent to cure / stabilize EMR and the results showed that manganese-bearing mineral in $\mathrm{EMR}, \mathrm{MnSO}_{4} \cdot 2 \mathrm{H}_{2} \mathrm{O},\left(\mathrm{NH}_{4}\right)_{2} \mathrm{Mn}\left(\mathrm{SO}_{4}\right)_{2} \cdot 6 \mathrm{H}_{2} \mathrm{O}$ and soluble $\mathrm{Mn}$, transformed into more stable insoluble mineral phases such as manganese calcium pyroxene $\left(\mathrm{CaMnSi}_{2} \mathrm{O}_{6}\right)$ and manganese silicate $\left(\mathrm{MnSiO}_{3}\right)$ after curing by PC32.5R. Meanwhile, hydrated gel can bind all the components in EMR and effectively inhibit the dissolution of Mn in EMR solidified body. Some studies say that cement has poor fixation effect on ammonia nitrogen in electrolytic manganese slag, and the solidification after treatment will produce different degrees of volume increase, and more land resources will be wasted in the subsequent stacking process. EMR-cement gel system has limited curing capacity for $\mathrm{NH}_{4}{ }^{+}$and the solidified body releases $\mathrm{NH}_{3}$ for a long time, which is easy to cause secondary pollution and is not conducive to the production and utilization of resource products. Zhou et al(2013) found that $\mathrm{CaO}$ is safer and more convenient than $\mathrm{NaOH}$ by studying the effect of additive types on $\mathrm{Mn}^{2+}$ solidification and ammonia nitrogen removal efficiency. With the analysis of immobilization mechanism. Du et al(2020) discovered that calcium oxide and sodium bicarbonate are beneficial to immobilize the soluble manganese of precipitation and oxidation products. The chemical stability experiment process is shown in Fig. 2. In practice, lime is not used solely for the cementation and solidification of EMR, and is mostly used in combination with fly ash, cement and other materials(Malviya et al, 2006). The curing efficiency of EMR-based cementitious materials ( EMR-P) prepared by Lan et al(2021) for ammonia and manganese is over $95 \%$, and its unconfined compressive strength is over $18 \mathrm{MPa}$, This is a new method for filling electrolytic manganese slag in mines. The technical process is shown in Fig. 3 below. The solidification and stabilization of $\mathrm{Mn}^{2+}$ and $\mathrm{NH}_{4}{ }^{+}-\mathrm{N}$ in electrolytic manganese slag by Shu et al(2018). using $\mathrm{MgO}$ and different phosphate resources showed that $\mathrm{Mn} 2+$ was mainly stable in the form of $\mathrm{Mn}\left(\mathrm{H}_{2} \mathrm{PO}_{4}\right)_{2} \cdot 2 \mathrm{H}_{2} \mathrm{O} \square \mathrm{Mn}_{3}\left(\mathrm{PO}_{4}\right) 2 \cdot 3 \mathrm{H}_{2} \mathrm{O} \square \mathrm{Mn}(\mathrm{OH})_{2} \square \mathrm{MnOOH}$, and

$\mathrm{NH}_{4}{ }^{+}-\mathrm{N}$ was stable in the form of $\mathrm{NH}_{4} \mathrm{MgPO}_{4} \cdot 6 \mathrm{H}_{2} \mathrm{O}$. The experimental principle diagram is shown in Fig. 4 below. Xue et al(2020) synthesized a new composite cementitious material with ground granulated slag, 
clinker, lime and EMR as raw materials. The analysis shows that gypsum is conducive to the rapid stability of heavy metals (except manganese). At the same time, CSH gel can effectively immobilized all heavy metals by HM-gel reaction, thus ensuring the environmental protection of the new material. Similarly, Zhang et al(2020) used blast furnace slag, red mud and carbide slag as stabilization / solidification ( S / S ) agents to treat electrolytic manganese slag. The principle is shown in Fig. 5 . The charge balance effect produced $\mathrm{Mn}_{2} \mathrm{SiO}_{4}$ and $\mathrm{Ca}_{4} \mathrm{Mn}_{4} \mathrm{Si}_{8} \mathrm{O}_{24}$, and formed new chemical bonds. Meanwhile, $\mathrm{Mn}^{2+}$ was oxidized to more stable $\mathrm{MnO}_{2}$.

\subsubsection{Resource utilization}

Because the composition of EMR is becoming more and more complex, its harmless treatment is becoming more and more difficult, and meanwhile, in order to alleviate the great pressure on the environment caused by the slag, some scholars have carried out a large number of EMR resource utilization work. The recycle and utilization of manganese in EMR is an important way to make full use of the slag. Biological method(Lan et al, 2021) acid leaching method(He et al,2020) water washing precipitation method(Baumgartner et al, 2014) are commonly used. Due to its mineral composition, EMR is mostly recycled as cement materials, road base, brick making materials, heavy metal adsorption materials and chemical fertilizer production in agricultural field.

\section{$\otimes$ Manganese recovery}

In recent years, because of the increasing lack of natural resources and increasing attention to environmental protection. The recycle of manganese from waste residue, by extracting $\mathrm{Mn}$ with heated sulfuric acid or hydrochloric acid solution as solvent, has attained more and more attention. Li et al(2015) used it as raw material to produce $\mathrm{MnO}_{2}$ by two-step method. The recycling process is shown in Fig. 5 . The XRD spectrum of $\mathrm{MnO}_{2}$, synthesized by EMR, shows that the characteristics of $\mathrm{Y}-\mathrm{MnO}_{2} \mathrm{XRD}$ spectrogram no other phase is detected, indicating that the purity of the final product is high. EDX analysis proved that the purity of the finished product is as high as $90.3 \%$, which can be directly used as chemical raw materials or raw materials to manufacture electrode materials. In the study of ultrasonicassisted extraction of manganese from EMR, Li et al $(2008)^{[42]}$ found that particle size parameters had the greatest influence on the extraction effect of manganese. Under specific extraction conditions, the efficiency of ultrasonic extraction of manganese could reach about $90 \%$, which proved that ultrasonicassisted extraction technology was more advantageous than traditional technology.

\section{\Cement material}

Wang et al(2013) added EMR as an activator to Ground granulated blastfurnace slag (GGBS) to prepare EMR-GGBS cement. Through the research on the activity index and compressive strength, it shows that the cement strength exceeds that of slag silicate cement (P.S) 32.5 levels, even reaching the level of P. S 42.5 and 52.5. The sulfur concrete prepared by Wang et al(2014) from EMR has high compressive strength and good durability. EMR, aggregate and modified sulfur are uniformly dispersed to form a 
compact packing structure. The detection showed that the leaching content of heavy metal ions was lower than the specified value in the national integrated wastewater discharge standard ( GB8978-1996), and it was not harmful to the environment.

\section{Q Road base material}

Zhang et al(2019) used EMR and other solid wastes to prepare road base materials. The preparation process is shown in Fig. 7(Zhang et al, 2019). The experiment proved that EMR-RM-CS had high unconfined compressive strength and durability, and the leaching test results were in line with China 's groundwater standards, indicating that EMR-RM-CS system could solidify heavy metals well, providing a new direction for the resource utilization of EMR. Chen et al(2021) verified the feasibility of the application of EMR in highway subgrade. In order to remove manganese and ammonia nitrogen in EMR, $10 \%$ lime was used for curing treatment. Considering that the slope height in actual is generally $8 \mathrm{~m} \sim$ $12 \mathrm{~m}$, combined with the stability calculation results of numerical simulation, they put forward a section scheme, manganese slag highway slope height of $10 \mathrm{~m}$ and slope ratio of $1: 1$, and the calculation results showed that heavy rainfall will also affect the stability of manganese slag slope at the same time.

\section{\ Autoclaved Brick/Permeable Brick}

Du and others(2014) used EMR to produce autoclaved bricks. Under the conditions of EMR mass ratio of $30-40 \%$, cement mass ratio of $10.5-12 \%$, formation pressure of $15-20 \mathrm{Mpa}, \mathrm{W} / \mathrm{C}$ ratio of 0.4 and steam pressure of $1.2-1.5 \mathrm{Mpa}$, the compressive strength of autoclaved bricks is greater than $15 \mathrm{Mpa}$, dry shrinkage is less than $0.11 \%$, compressive strength loss is less than $10 \%$ and weight loss is less than $2 \%$. Experiments showed that the compressive strength and leaching toxicity of the autoclaved brick meet the requirements of relevant standards. The $\mathrm{C}-\mathrm{S}-\mathrm{H}$ gel and calcium zirton in the brick sample form the pressure strength mechanism. Wang et al(2019) prepared non-sintered permeable brick with electrolytic manganese slag as raw material. The study found that the compressive strength of non-sintered permeable brick can reach 3.53Mpa after 28 days, meeting the requirements of GB / T25993-2010. Ammonia can also be recycled during the pretreatment of EMR. The leaching experiment of permeable brick showed that these harmful substances in EMR have been effectively solidified.

$\nabla$ Heavy metal adsorption material

$\mathrm{Li}$ et al(2015) took EMR as raw material to prepare $\mathrm{MnO}_{2}$ by two-step method. The XRD spectrum of $\mathrm{MnO}_{2}$ synthesized by EMR showed the characteristics of $\mathrm{Y}-\mathrm{MnO}_{2}$ XRD spectra and no other phase was detected which means that the purity of the final product was high. A kind of EMR-made calcium silicate hydrate has been prepared during the preparation process, which has good adsorption properties for diluted $\mathrm{Mn}^{2+}$ and phosphate ions in water and is a potential large-scale wastewater treatment material. Lan et al(2021) prepared a new material ( A-EMS ) for removing heavy metals by ball milling active electrolytic manganese slag. Adsorption and removal mechanisms of heavy metals are shown in Fig. 9. Powder A-EMS has remarkable effect on removing heavy metals in wastewater. Block A-EMS (porous brick ) can be used to build barrier walls to prevent heavy metal leaching in tailings ponds. The leaching 
toxicity test results can meet the national standard ( GB / T3838-2002 ) limit. Therefore, A-EMS can be widely used to remove heavy metals in wastewater, intercept and solidify heavy metals in mine wastewater.

Although the harmless treatments and resource utilizations of EMR provide many directions for future development, most of them are in the laboratory stage. The resource utilization of manganese slag is difficult to mass production, and the efficiency of manganese slag treatment is difficult to achieve expectations. Another reason is that the cost of harmless or resource treatment is too high or the process is too complex to produce economic benefits. A single technology will not meet the huge demand of electrolytic manganese industry. Only by effectively integrating various technologies can the problem of electrolytic manganese slag be fundamentally solved. Among them, the building materials industry has the strongest consumption ability, and can carry out technical research in this field. The research on new environmental protection bricks in this paper is helpful to the large consumption of electrolytic manganese slag and create certain economic value.

\subsection{Research on new environmental protection bricks}

The reasonable disposal solution of EMR is of great significance to promote the development of electrolytic manganese industry and is more conducive to the restoration of ecological environment. As the largest bulk solid waste consumption industry, building materials industry can effectively solve the consumption problem of EMR. The main oxide compositions of electrolytic manganese slag are $\mathrm{SiO}_{2}$, $\mathrm{Al}_{2} \mathrm{O}_{3}, \mathrm{Fe}_{2} \mathrm{O}_{3}$ and $\mathrm{CaO}$. It is a good raw material for building materials. Many researchers have explored the building materials utilization of electrolytic manganese slag, but there are few environmental protection applications with low cost and easy popularization. This paper introduces a new environmental protection brick manufactured by EMR using environment-friendly calcination technology.

To be specific, the individual pollutants, physical properties and environmental characteristics of sintered bricks synthesized by this method were studied. At the same time, the sintering behavior and crystallization of all products including EMR were mainly studied. The leaching study of bricks composed of EMR was also carried out and analyzed. This study provides an effective method for the utilization of EMR resources.

\section{Materials And Methods 3.1. Raw Materials}

EMR was provided by Chongqing a electronics limited liability company in Chongqing, China, the average grain size (d50) was 100 micrometers, water content was $17.8 \%$. Clay was provided by a shale company in Chongqing, the average grain size (d50) was 130 micrometers. Pulverized coal was provided by a coalfired power plant in Chongqing, the calorific value was $4500 \mathrm{kcal}$.

\subsection{Mixing ratios and preparation methods}




\subsubsection{Mixing ratios}

The mixing proportion of sintered bricks containing EMR is presented in Table 1. As indicated in it,78.5\%, $88.5 \%, 98.5 \%$ clay, and $0 \%, 10 \%, 20 \%$ EMR, and $1.5 \%$ pulverized coal alongside 0.22 water to materials ratio were used in all samples.

Table 1

Mixing proportion of EMR brick /\%

\begin{tabular}{|llll|}
\hline Manganese residue & Clay & Pulverized coal & Water to materials ratio \\
\hline 0 & 98.5 & 1.5 & 0.22 \\
\hline 10 & 88.5 & 1.5 & \\
20 & 78.5 & 1.5 & \\
\hline
\end{tabular}

\subsubsection{Preparation of the EMR sintered brick}

The clay, EMR and pulverized coal were blended homogeneously by mixing using a blender machine for about $30 \mathrm{~s}$, and then water was added and slowly mixed for about 2 minutes. The molding size of specimens was $240 \mathrm{~mm} \times 115 \mathrm{~mm} \times 53 \mathrm{~mm}$ and molding pressure is $4-6 \mathrm{MPa}$, then specimens were demolded and sintered in a muffle furnace at $950-1000^{\circ} \mathrm{C}$ for $105-115$ min. After sintering, the brick specimens were cooled by nature air.

\subsection{Test methods}

\subsubsection{Mechanical property}

The compressive strength was determined by a universal testing machine according to the Chinese standard "sintered common bricks" (GB/T 5101-2017).

\subsubsection{Shrink rate property}

Shrink rate $=($ Volume before calcination - Volume after calcinations $) /$ Volume before calcination $\times 100 \%$.

\subsubsection{Methods of structural characterization and composition}

The hydrated and crystalline minerals of the brick samples were studied using X-ray powder diffraction (XRD) in an X'Pert PRO diffractometer (PANalytical).

According to the ASTEREO SCAN440, Leica Cambridge Ltd, X-ray spectroscopy helped scanning electron microscope (SEM) is used to investigate the morphology of the hydration products.

The chemical bonds of hydration product were analyzed by America Thermo brand Fourier-Infrared (FT$\mathrm{IR})$. 
The EMR was dried at $100 \pm 5^{\circ} \mathrm{C}$ to obtain the dry base sample. The chemical compositions of the EMR and shale soil were analyzed by X-ray fluorescence spectrometer (XRF).

\subsubsection{Natural radionuclides}

The samples were tested for natural radionuclides using a high-resolution and low-background gamma spectrometry, and 40K (1460 keV). 226Ra (via $352 \mathrm{keV}$ of 214Pb) and 234Th (63.3 keV). Furthermore, I $\mathrm{Ra}$ and $I_{r}$ the activity concentration indices were established to analyze the possible radiological risks

\subsubsection{Leaching property}

Based on the manganese ore electrolysis process of the electronics company (Chongqing, China), it is known that the characteristic pollutants of EMR mainly are ammonia nitrogen and manganese, so it is pretreated with general aqueous solution, and COD, ammonia nitrogen and manganese in its leaching solution were tested by general leaching. Particular pollutants leached from brick specimens must satisfy the Chinese standard "Soil environmental quality risk control standard for contamination of development land"(GB36600-2018) and "Integrated water discharge standard" (GB 8978-1996). Therefore, the samples were pre-treated according to the national standard method to investigate the environmental security.

\section{Results And Discussion}

\subsection{Basic physical properties of EMR 4.1.1 Chemical composition analysis}

Table 2

chemical composition analysis of raw materials /\%

\begin{tabular}{|llllllll|}
\hline Material & $\mathrm{SiO}_{2}$ & $\mathrm{Al}_{2} \mathrm{O}_{3}$ & $\mathrm{SO}_{3}$ & $\mathrm{Fe}_{2} \mathrm{O}_{3}$ & $\mathrm{MnO}$ & $\mathrm{BaO}$ & $\mathrm{K}_{2} \mathrm{O}+\mathrm{Na}_{2} \mathrm{O}$ \\
\hline EMR & 22.79 & 8.26 & 24.31 & 20.48 & 9.77 & 1.45 & 2.09 \\
\hline Shale soil & 55.46 & 24.79 & 0.37 & 11.96 & - & - & 2.78 \\
\hline
\end{tabular}

The chemical composition of the EMR and shale soil was analyzed by XRF. The analysis results are shown in the Table 2. It is show that the main chemical components of EMR are silicon dioxide, alumina, sulfur trioxide, iron oxide and manganese oxide, among which the contents of sulfur trioxide, iron oxide and manganese oxide arerelatively high. As well as, aside from $\mathrm{SO}_{3}$, other chemical compositios are consistent with shale soil.

\subsubsection{General leaching test of manganese residue}

Leaching test results reported in Table 3 show that concentrations of ammonia nitrogen and manganese in the manganese residue leaching solution were $1256 \mathrm{mg} / \mathrm{L}$ and $8120 \mathrm{mg} / \mathrm{L}$, respectively. Both exceeded Chinese standards outlined in the "Integrated wastewater discharge standard" (First grade standard) (GB 
8978-1996). Therefore, a clean treatment technology for recycled EMR in sintered bricks had been carried out to eliminate environmental risks.

Table 3

Test results of EMR general leaching

\begin{tabular}{|lll|}
\hline Items & $\begin{array}{l}\text { Result } \\
(\mathbf{m g} / \mathrm{L})\end{array}$ & $\begin{array}{l}\text { "Integrated wastewater discharge standard " ( first grade standard) } \\
(\text { GB 8978-1996) }\end{array}$ \\
\hline COD & 46.7 & 60 \\
\hline $\begin{array}{l}\text { Ammonia } \\
\text { nitrogen }\end{array}$ & 1256 & 15 \\
\hline Mn & 8120 & 2.0 \\
\hline
\end{tabular}

\subsection{Properties of EMR brick}

\subsubsection{Appearance of EMR sintered brick}

As it shown in Fig. 11, the surface color of bricks containing EMR looks darker than the clay raw material, and hematite resulted in orange-colored red brick bodies. This is because of EMR contains copious amounts of iron oxides, brick samples appear yellowish-brown or reddish-brown after high-temperature sintering.For this reason, with increasing levels of EMR, the color of the sintered bricks prepared with EMR gradually deepens from brown-yellow to gray-black. Therefore, the color of sintered bricks with EMR below $20 \%$ appears the same as brick sintered with pure clay. So, the maximum EMR content in the brick were set to $20 \%$.

\subsubsection{Shrinkage rate of EMR sintered brick}

Figure 12 shows the shrinkage rates of the sintered bricks increased as the EMR levels increased. The shrinkage rates of bricks containing 10 and $20 \%$ EMR were 5.7 and $7.6 \%$ respectively, higher than the control group ( $0 \%$ EMR). The shrinkage rates of the samples with $20 \%$ EMR exceeds by $10 \%$ to approximately $33 \%$. Those increases were due to several factors. Firstly, the loss on ignition increased the decomposition of calcium sulfate and other sulfides in the manganese residue. Secondly, the decomposition of sulfides such as calcium sulfate in the manganese residue accelerated for clays, which indicated clay minerals promoted the decomposition of sulfates and further increased the loss on ignition. Thirdly, liquid phase increased during sintering, which makes the green body that produces the shrinkage. So, as EMR content increased, the liquid phase amount increased, and assisted specimen sintering, which increased the density and led to shrinkage increases.

\subsubsection{Basic physical properties of EMR sintered brick}


Table 4

Test results of basic physical properties

\begin{tabular}{|lll|}
\hline Samples & Compressive strength $/ \mathrm{MPa}$ & Radioactivity \\
\hline Blank control group & 14.8 & $\mathrm{I}_{\mathrm{Ra}}=0.3 \varangle \mathrm{I}_{\mathrm{r}}=0.5$ \\
\hline $10 \%$ manganese residue brick & 17.6 & $\mathrm{I}_{\mathrm{Ra}}=0.2 \varangle \mathrm{I}_{\mathrm{r}}=0.3$ \\
\hline $20 \%$ manganese residue brick & 20.5 & $\mathrm{I}_{\mathrm{Ra}}=0.3 \otimes \mathrm{I}_{\mathrm{r}}=0.4$ \\
\hline Standard value & $\geq 10.0$ & $\mathrm{I}_{\mathrm{Ra}} \otimes 1.0 \square \mathrm{I}_{\mathrm{r}} \otimes 1.0$ \\
\hline
\end{tabular}

According to the test results in Table 4, the compressive strength of sintered bricks with $10 \%$ and $20 \%$ EMR were 17.6 and $20.5 \mathrm{MPa}$, respectively, meeting the requirements of the national standard "sintered common bricks" (GB/T 5101-2017). As well as, much higher than that of the control group (14.8 MPa). The radioactivity limits of sintered bricks with $20 \%$ EMR were $\mathrm{I}_{\mathrm{Ra}}=0.3$ and $\mathrm{I}_{\mathrm{r}}=0.4$, which all meet the relevant requirements of the national standard "Limits of radionuclides in building materials" (GB 65662010) having the similar radioactive level with the control group $\left(I_{R a}=0.3, I_{r}=0.5\right)$. This is mainly due to the fact that $\mathrm{EMR}$ is rich in $\mathrm{Fe}_{2} \mathrm{O}_{3}$ and $\mathrm{K}_{2} \mathrm{O}$. It can greatly promote the particles re-arrangement and transfer in EMR system and promote the materials sintering, reducing the sintering temperature and improving the compressive strength of the bricks. So the compressive strength of brick with $20 \%$ EMR is higher than the brick specimens with $10 \%$ EMR. However, with the increase of EMR, the radioactivity also appropriately increases.

\subsubsection{Moulding pressure of EMR sintered brick properties}

Table 5

Moulding pressure of $20 \%$ EMR sintered brick properties

\begin{tabular}{|c|c|c|c|c|c|}
\hline \multirow[t]{2}{*}{ NO. } & \multirow{2}{*}{$\begin{array}{l}\text { Moulding } \\
\text { pressure } \\
(\mathrm{MPa})\end{array}$} & \multirow{2}{*}{$\begin{array}{l}\text { Dry } \\
\text { density } \\
\left(\mathrm{kg} / \mathrm{m}^{3}\right)\end{array}$} & \multicolumn{2}{|c|}{ Strength(MPa) } & \multirow{2}{*}{$\begin{array}{l}\text { Frost resistance } \\
\text { (Strength loss rate } \\
\%)\end{array}$} \\
\hline & & & $\begin{array}{l}\text { Flexural } \\
\text { strength }\end{array}$ & $\begin{array}{l}\text { Compressive } \\
\text { strength }\end{array}$ & \\
\hline 1 & 6 & 1630 & 6.7 & 21.2 & 1.53 \\
\hline 2 & 5 & 1543 & 5.4 & 18.5 & 1.66 \\
\hline 3 & 4 & 1439 & 4.3 & 13.6 & 1.94 \\
\hline
\end{tabular}

From Table 5, the dry density and compressive strength of brick specimens containing EMR increase with the increase of moulding pressure. However the frost resistance was constantly decrease. This shows that the moulding pressure is more effective to the sintered brick containing EMR, and the optimal moulding pressure is 5-6 MPa. So, the properties of sintered brick containing $20 \%$ EMR were presented in Table 6. It shows that frost-resistance, water absorption and radionuclide limits of the sintered bricks with $20 \%$ EMR were all meet the MU20 grade of Chinese standard "Fired common bricks" (GB5101). 
Table 6

Other properties of $20 \%$ EMR sintered brick

\begin{tabular}{|lllll|}
\hline NO. & Test index & Measured value & Standard value & Judgement result \\
\hline 1 & Strength grade & 21.2 & MU20 & Qualified \\
\hline 2 & Frost-resistance & Strength loss rate:1.53\% $(\leq 25 \%)$ & Qualified \\
\cline { 3 - 5 } & & Nnmber of freezing damage:0 & $\leq 1$ & \\
\hline 3 & Water absorbtion & $10.3 \%$ & $\leq 20 \%$ & Qualified \\
\hline 4 & Radionuclide Limits & $\mathrm{I}_{\mathrm{Ra}} \leq 1$ & & Qualified \\
& & $\mathrm{I}_{\mathrm{r}} \leq 1$ & \\
\hline
\end{tabular}

\subsubsection{X-ray diffraction pattern of EMR sintered brick}

The XRD spectrum of Fig. 13 shows that the major crystalline phases present in sintered bricks were quartz $\left(\mathrm{SiO}_{2}\right)$, hematite $\left(\mathrm{Fe}_{2} \mathrm{O}_{3}\right)$, anhydrite $\left(\mathrm{CaSO}_{4}\right)$ and albite, which formed the main mineral framework of the EMR bricks. The crystalline phases were also responsible for the physical properties and mechanical strength of bricks. After mixing with EMR and sintering at high temperature, the content of gypsum dihydrate in the system is greatly reduced. This also verifies that after dehydration at high temperature, the gypsum decomposes to calcium oxide and sulfur trioxide. At the same time, the content of $\mathrm{SiO}_{2}$ decreases gradually. This is mainly due to the addition of EMR, resulting in the reduction of $\mathrm{SiO}_{2}$ proportion. In addition, the residual silicon forms low eutectic glass phase with sodium and calcium, which leads to the further reduction of $\mathrm{SiO}_{2}$ content. As well as, the diffraction peak intensity of albite increases gradually with the EMR content increases. The main reason is the content of albite increases gradually. The spectrum analysis is also consistent with the results of basic physical properties such as compressive strength and shrinkage.

\subsubsection{SEM patterns of EMR sintered brick}

The SEM patterns in Fig. 14 shows that the grain size and pore distribution of the specimens is consistent, and uniform, and there are glass phases among the particles. In addition, a large number of granular and short rod-shaped crystals can be clearly seen in the glass phase. The details can be seen in the Fig. 14 (control group) that the sections of sintered bricks without EMR were mostly the small silicate layers and crystal like minerals particles under the $950^{\circ} \mathrm{C}$ sintering temperature. Fig. 14(10\% EMR) showed the sections of sintered bricks with $10 \%$ EMR sintered bricks were mostly the small silicate layers and crystal like minerals particles under the sintering temperature of $950^{\circ} \mathrm{C}$. For the brick samples containing 20\% EMR, Fig. 14 also shows that the molten glass phase wrapped and cemented the fine crystal-like mineral particles, filled the small pores between materials and made them close to each other. 
The main reason is that the microstructure of sintered brick becomes more compact after adding EMR, and the compactness of sintered brick with $20 \%$ EMR is obviously higher than that with $10 \%$ EMR.The sintering mechanism is as follows the particles combine with each other to form the skeleton of the green body. In the sintering process, EMR can reduce the sintering temperature and produce molten liquid in advance. The higher the temperature is, the more glass phase can be produced.Under the action of capillary force and surface tension, glass phase can fill the gaps between particles, seal part of surface pores, bond particles and form a network structure, thus reducing the porosity of the sample and making the sintered brick compact. So, the brick specimens with EMR have higher compressive strength and lower shrinkage rate(Luo et al, 2020).

\subsubsection{Fourier infrared spectrum pattern of EMR sintered brick}

According to infrared spectrum in Fig. 14, the absorption peak at $1134.2 \mathrm{~cm}^{-1}$ is related to Si-O asymmetric stretching vibration. The peak at $761.4 \mathrm{~cm}^{-1}$ is corresponding to Si-O-Si symmetric stretching vibration. The peaks atat $1629.8 \mathrm{~cm}^{-1}$ and $3487.3 \mathrm{~cm}^{-1}$ are contribute to $\mathrm{H}-\mathrm{O}-\mathrm{H}$ symmetric stretching vibration respectively(Gijbels et al, 2019). It can be seen that compared with the control group, the infrared spectrum of quartz with EMR is wider and the peak intensity is lower. Therefore, its crystallinity is general, and its quartz content is lower than that of the control group. The observation indicates that the content of $\mathrm{SiO}_{2}$ decreases with the increase of EMR content. Meanwhile, the absorption peaks of $\mathrm{H}-\mathrm{O}-\mathrm{H}$ decreases at $1629.8 \mathrm{~cm}^{-1}$ and $3487.3 \mathrm{~cm}^{-1}$, were indicating that the crystal water in calcium sulfate dihydrate decomposes gradually at high temperature. The absorption peak at $2300-2400 \mathrm{~cm}^{-1}$ is S-H symmetric stretching vibration. The peak around $2300-2400 \mathrm{~cm}^{-1}$ was not detected at bricks with $10 \%$ EMR specimen, it may due to the fact that the right amount of $\mathrm{Fe}_{2} \mathrm{O}_{3}, \mathrm{~K}_{2} \mathrm{O}$ can greatly promote the particles re-arrangement and promote the materials sintering, so the sulphydryl compounds also participated in this reaction. But when the bricks mixed with $20 \%$ EMR, itself sulphydryl compounds to be introduced too much, which caused this FTIR spectrum data phenomenon.

\subsection{Leaching environmental safety properties of EMR sintered brick}


Table 7

Test results of sintered brick's leaching properties

\begin{tabular}{|c|c|c|c|c|}
\hline \multirow[t]{2}{*}{ Items } & \multicolumn{3}{|c|}{ Test result(mg/L) } & \multirow{2}{*}{$\begin{array}{l}\text { "Integrated wastewater } \\
\text { discharge standard " (first grade standard) } \\
\text { (GB 8978-1996) }\end{array}$} \\
\hline & $\begin{array}{l}\text { Control } \\
\text { group }\end{array}$ & $\begin{array}{l}10 \% \\
\text { manganese } \\
\text { residue brick }\end{array}$ & $\begin{array}{l}20 \% \\
\text { manganese } \\
\text { residue brick }\end{array}$ & \\
\hline COD & 27.6 & 11.8 & 24.7 & 60 \\
\hline $\begin{array}{l}\text { Ammonia } \\
\text { nitrogen }\end{array}$ & $0.05 \mathrm{~L}$ & $0.05 \mathrm{~L}$ & 0.09 & 15 \\
\hline $\mathrm{Mn}$ & $0.01 \mathrm{~L}$ & $0.01 \mathrm{~L}$ & $0.01 \mathrm{~L}$ & 2.0 \\
\hline $\mathrm{Ni}$ & 0.04 & 0.05 & 0.06 & 1.0 \\
\hline $\mathrm{Cu}$ & 0.18 & 0.17 & 0.19 & 0.5 \\
\hline As & 0.02 & 0.02 & 0.03 & 0.5 \\
\hline
\end{tabular}

According to the test results of leaching solution of sintered bricks in Table 7, the contents of COD, ammonia nitrogen, $\mathrm{Mn}, \mathrm{Ni}, \mathrm{Cu}$ and $\mathrm{As}$ in the leaching solution of sintered bricks with $10 \%$ and $20 \% \mathrm{EMR}$ were $11.8,0.05 \mathrm{~L}, 0.01 \mathrm{~L}, 0.05,0.17,0,02 \mathrm{mg} / \mathrm{L}$ and $24.7,0.09,0.01 \mathrm{~L}, 0.06,0.19,0.03 \mathrm{mg} / \mathrm{L}$, respectively. The pollutants are far below the first-level standard requirements of the national standard "Integrated wastewater discharge standard" (GB 8978-1996). The main reason is that the $\mathrm{Fe}_{2} \mathrm{O}_{3}, \mathrm{~K}_{2} \mathrm{O}$ is rich in $\mathrm{EMR}$, it forms a liquid phase at lower temperatures. The contaminations in the sintered brick system can be efficiently wrap up by this

technology, so the heavy metal prepared by EMR as raw material will not cause secondary pollution to the environment(Zhang et al, 2019; Li et al, 2020;Xu et al, 2019; Leiva et al, 2018;Arroyo et al, 2020).

In addition, according to the requirements of the "Identification Standards for Solid Wastes-General Rules"(GB 34330-2017), when there is no national pollution control standard or technical specification, the content of harmful components in the product should not be higher than that in the product produced with substituted raw materials. Meanwhile, according to the test results of leaching solution in Table 7, the content of COD, ammonia nitrogen, manganese, $\mathrm{Mn}, \mathrm{Ni}, \mathrm{Cu}$ and $\mathrm{As}$ in the sintered bricks with $10 \%$ EMR did not exceed that in the control group, and mixed $20 \%$ also meet the first grade standard. Therefore, the maximum contents of EMR is $20 \%$ for brick application.

\subsection{Practical production flow chart of EMR sintered brick}

Figure 16 shows the practical production flow chart of bricks containing EMR. Preliminary results utilized bricks with the following compositions (by mass): $20 \%$ EMR, $78 \%$ shale, and $2 \%$ coal ash were used. EMR and shale were initially broken with a jaw crusher, rotary screen, and fine crusher. Then all raw materials were mixed using a double shaft mixer, transported to a hydraulic molding machine, the green bricks were 
prepared. After molding, the brick samples were placed into a tunnel kiln for calcination that led to successful fabrication of EMR bricks.

\section{Conclusions}

Based on the review of the current solidification and stabilization treatment methods and resource utilization methods of EMR, the physical properties and leaching properties of EMR were evaluated, and the sintering behavior and crystallization process of EMR bricks were studied:

1. At present, the harmless treatment and resource utilization of EMR are diversified, but most of them are in the laboratory stage. The complex production process and high production cost limit the resource utilization of EMR. It is necessary to integrate a variety of processes to make EMR consume in large quantities. In this study, EMR is used as raw material to prepare sintered bricks for building materials industry, which can be effectively disposed.

2. The particular pollutants of EMR were studied in details, and the contents of ammonia nitrogen and manganese in the leaching solution of EMR were $1256 \mathrm{mg} / \mathrm{L}$ and $8120 \mathrm{mg} / \mathrm{L}$, respectively. The pollutants both exceeds the standard requirements of comprehensive sewage discharge standards and poses environmental safety risks.

(3) The compressive strength of sintered bricks prepared with $10 \%$ and $20 \%$ EMR meets the requirements of the national standard "sintered common bricks" (GB/T 5101). The radioactivity limit of sintered bricks with $20 \%$ EMR also meets the relevant requirements of the national standard "Limits of radionuclides in building materials" (GB 6566-2010). This is mainly due to the fact that EMR is rich in $\mathrm{Fe}_{2} \mathrm{O}_{3}, \mathrm{~K}_{2} \mathrm{O}$, these substances can greatly promote the particles re-arrangement and transfer in EMR system and promote the materials sintering, reducing the sintering temperature, accelerating sintering and improving the product's all performances.

(4) The particular pollutants content of COD, ammonia nitrogen, manganese, $\mathrm{Ni}$, $\mathrm{Cu}$ and $\mathrm{As}$ in bricks prepared with $20 \%$ EMR were equal to that in blank sintered brick. The concentration of these pollutants met the requirements of the first-level standard requirements of the national standard "Integrated wastewater discharge standard" (GB 8978). Therefore, the sintered bricks prepared with $20 \%$ EMR will be no secondary pollution.

\section{Declarations}

-Ethical Approval: This study does not contain any studies with human participants and/or animals.

-Consent to Participate:Written informed consent was obtained from individual participants.

-Consent to Publish:Not applicable. 
-Authors Contributions:Ke Liu mainly contribute to study design, experimental studies,data analysis and manuscript editing and revision. Chao-qiang Wang mainly contribute to material preparation,manuscript preparation and manuscript editing and revision. De-ming Huang mainly contribute to experimental studies,statistical analysis and manuscript editing and revision. Qi-cong Huang mainly conducted experimental research and manuscript editing. Pei-xin Wang mainly did data analysis and manuscript editing. Xu-dong Mei mainly did data analysis and manuscript editing. Yu Chen mainly did experiments and edited manuscripts. Shu-chun Li mainly contribute to experimental studies,statistical analysis. Kai Wu mainly contribute to manuscript editing and revision. All authors read and approved the final manuscript.

-Funding:Opening Project of Key Laboratory of Solid Waste Treatment and Resource Recycle, Ministry of Education (20kfck03), and Opening Project of Key Laboratory of Urban Pollutant Conversion, Chinese Academy of Sciences (KLUPC-KF-2020-2) and Key Laboratory of Advanced Civil Engineering Materials (Tongji University), Ministry of Education (202103),Youth Project of Science and Technology Research program of Chongqing Education Commission of China. (No. KJQN202100723)

-Competing Interests:We declare that we have no competing interests.

-Availability of data and materials :All data generated or analysed during this study are included in this published article.

\section{References}

1. Arroyo F, Luna-Galiano Y, Leiva C, Vilches LF, Fernández-Pereira C (2020) Environmental risks and mechanical evaluation of recycling red mud in bricks. Environmental Research 186:109537

2. Banerjee A, Ziv B, Luski S, Aurbach D, Halalay IC (2017) Increasing the durability

3. of Li-ion batteries by means of manganese ion trapping materials with nitrogen functionalities.Power Sources.341:457-465

4. Baumgartner SJ, Groot DR (2014) The recovery of manganese products from ferromanganese slag using a hydrometallurgical route. J S Afr Inst Min Metall, Johannesburg 114(4):331-340

5. Brantley FE, Rampacek C (1968) Manganese and iron recovery from leach solutions.US Patent No.3397130

6. Pereira CF, lolanda D (2018) Cristina Silveira. Bioleaching of toxic metals from sewage sludge by coinoculation of Acidithiobacillus and the biosurfactant-producing yeast Meyerozyma guilliermondii. Environ. Manag. 211, 28-35

7. Chen $\mathrm{H}$, Liuauthor $\mathrm{R}$, Liuauthor $\mathrm{Z}$, Shuauthor J, Taoauthor $\mathrm{C}$ (2015) Immobilization of $\mathrm{Mn}$ and $\mathrm{NH}_{4}{ }^{+}{ }^{-} \mathrm{N}$ from electrolytic manganese residue waste. Environmental Science \& Pollution Research 23:1235212361

8. Chen M, Wei J, Jia L, Yao Q, Chen Y (2021) Study On Solidification Treatment of Electrolytic Manganese Slag And Numerical Simulation of Slope Stability. 10.21203/rs.3.rs-521014/v1. 
PPR:PPR349350.

9. Chuwit Napia S, Theerawat J, Chai et al (2012) Leaching of heavy metals from solidified waste using Portland cement and zeolite as a binder. Waste Manag 32(7):1459-1467

10. Cong Y, Dong QJ, Xiao KY, Chen JP, Gao YB, Yin JN (2018) Characteristics and Predicated Potential of Mn Resources in China. Earth Sci Front 25(3):118-137. (in Chinese)

11. Duan N, Dan ZG, Wang F, Pan CX, Zhou CB, Jiang LH (2011) Electrolytic manganese metal industry experience based China's new model for cleaner production promotion. Journal of Cleaner Production 19(17):2082-2087

12. Du B, Zhou CB, Duan N (2013) Recycling of electrolytic manganese solid waste in autoclaved bricks preparation in China. Mater Cycles Waste Manag 16:258-269

13. Du B, Zhou CB, Dan ZG, Luan ZK, Duan N (2014) Preparation and characteristics of steamautoclaved bricks produced from electrolytic manganese solid waste,Construction and Building Materials. 50:291-299

14. Du B, Hou D, Duan N et al (2015) Immobilization of high concentrations of soluble Mn(II) from electrolytic manganese solid waste using inorganic chemicals. Environ Sci Pollut Res 22:7782-7793

15. Feng Y, Liu F, Bao X (2006) Possibility of using manganese residue as one of cement setting retarder to replace part of gypsum. Cement 2:22-24

16. Gijbels Katrijn IR, Ion P, Yiannis SS (2019) Wouter Schroeyers. Alkali-activated binders based on ground granulated blast furnace slag and phosphogypsum. Constr Build Mater 215:371-380

17. Han Yao-cong (2018) Cui Xue-min, Lv Xue-sen, Wang Kai-tuo. Preparation and characterization of geopolymers based on a phosphoric-acidactivated electrolytic manganese dioxide residue. J. Clean. Prod. 205:488-498

18. He DJ, Shu JC, Wang R, Chen MJ, Wang R et al (2021) A critical review on approaches for electrolytic manganese residue treatment and disposal technology: Reduction, pretreatment, and reuse. J Hazard Mater 418:126235

19. He S, Liao C, Wang X et al (2020) Pressure Sulfuric Acid Leaching of Manganese-Rich Slag with Pyrite as Additive. Mining, Metallurgy \& Exploration 37:433-442

20. Hou Peng-kun, Zhi W (2012) Deng Cheng. Production of quasi-sulphoaluminate cementitious materials with electrolytic manganese residue.Cement Concrete Comp. 34: 248-254

21. Lan JQ (2006) A test to corn production with fertilizer of Mn-dregs. China's Manganese Ind 2:43-44

22. Lan Ji-rong, Wei SYanCXiao-hongZ, Zhang Tian DY C, Ye Heng-peng, Du Dong-yun, Hou Hao-bo. 2021. Bio-leaching of manganese from electrolytic manganese slag by Microbacterium trichothecenolyticum Y1: Mechanism and characteristics of microbial metabolites.Bioresource Technology, 319,124056

23. Lan JR, Sun Y, Tian H, Zhan W, Du YG, Ye HP, Du DY, Zhang TC, Hou HB (2021) Electrolytic manganese residue-based cement for manganese ore pit backfilling: Performance and mechanism. J Hazard Mater 411:124941 
24. Lan Ji-rong, Wei SYanCXiao-hongZ, Zhang Tian DY C, Ye Heng-peng, Du Dong-yun, Hou Hao-bo. 2021. Bio-leaching of manganese from electrolytic manganese slag by Microbacterium trichothecenolyticum Y1: Mechanism and characteristics of microbial metabolites.Bioresource Technology, 319,124056

25. Lan Ji-rong, Lu DYi-qieSYanF, Min Z Hou Hao-bo, Du Dong-yun. 2021. A novel method for solidification/stabilization of $\mathrm{Cd}(\mathrm{II}), \mathrm{Hg}(\mathrm{II}), \mathrm{Cu}(\mathrm{II})$, and $\mathrm{Zn}$ (II) by activated electrolytic manganese slag.Journal of Hazardous Materials409:124933

26. Leiva C, Rodriguez-Galán M, Arenas C, Alonso-Fariñas B, Peceño B (2018) A mechanical, leaching and radiological assessment of sintered bricks with a high content of fly ash. 44:1331313319Ceramics International11

27. Li CX, Zhong H, Wang S, Xue JR (2014a) Leaching behavior and risk assessment of heavy metals in a landfill of electrolytic manganese residue in Western Hunan, China. Hum Ecol Risk Assess $20: 1249-1263$

28. Li CX, Zhong H, Wang S et al (2015) Preparation of $\mathrm{MnO}_{2}$ and calcium silicate hydrate from electrolytic manganese residue and evaluation of adsorption properties. J Cent South Univ 22:24932502

29. Li H, Zhang ZH, Tang SP, Li YN, Zhang YK (2008) Ultrasonically assisted acid extraction of manganese from slag. Ultrason Sonochem 15(4):339-343

30. Li Jia S, Peng L, Ying JL, Heng-peng Y, Li S, Du Dongyun (2020) Synthesis of electrolytic manganese residue-fly ash based geopolymers with high compressive strength. Constr Build Mater 248:118489

31. Li TP, Xie HL, He XM, Zhou XZ (2007) Experimental study of calcined electrolysis manganese residue and fly ash complex admixture. Bull Chin Ceram Soc (in Chinese) 3:567-571

32. Luo Li-qun, Li Ke-yao,Fu Weng, Liu Cheng,Yang Si-yuan. Preparation, characteristics and mechanisms of the composite sintered bricks produced from shale, sewage sludge, coal gangue powder and iron ore tailings.Constr. Build. Mater. 232: 117250

33. Malviya R, Chaudhary R (2006) Factors affecting hazardous waste solidification /stabilization: A review. J Hazard Mater 137(1):267-276

34. Mu WH, Zhou XT, He S et al (2020) Solidification/Stabilization and Toxicity Leaching of Electrolytic Manganese Residue Using Composite Portland Cement...Non-Metallic Mines. 43:5-8. (in Chinese). 02

35. Nan Hu, De-Xin ZJi-FangD, Jun L, Yang Lu-Qing, Yin Jie (2009) Metal pollution in Huayuan river in hunan province in china by manganese sulphate waste residue. Bulletin of Environmental Contamination and Toxicology 83(4):583-590

36. Qian J, Hou P, Wang Z, Qu Y (2012) Crystallization characteristic of glass-ceramic made from electrolytic manganese residue. Wuhan Univ Technol eMater Sci Ed 27:45-49

37. Shu JC, Liu RL, Chen HL, Du J, Tao CY (2016) Solidification/stabilization of electrolytic manganese residue using phosphate resource and low-grade MgO/CaO. J Hazard Mater 317:267-274 
38. Shu Jian-cheng (2018) Wu Hai-ping, Liu Ren-long, Liu Zuo-hua, Li Bing, Chen Meng-jun, Tao Changyuan. Simultaneous stabilization/solidification of $\mathrm{Mn}^{2+}$ and $\mathrm{NH}_{4}{ }^{+}-\mathrm{N}$ from electrolytic manganese residue using $\mathrm{MgO}$ and different phosphate resource,Ecotoxicology and Environmental Safety. 148, 220-227

39. Silva Marcos AR, Mater Luciana, Souza-Sierra Maria M, Corrêa Albertina XR, Rafael S, Radetski Claudemir M (2007) Small hazardous waste generators in developing countries: use of stabilization/solidification process as an economic tool for metal waste water treatment and appropriate sludge disposal. J Hazard Mater 147(3):986-990

40. Tang Bin-wen, Shuai G, Wang Ya-guang, Liu Xiao-ming, Zhang Na (2019) Pore structure analysis of electrolytic manganese residue based permeable brick by using industrial CT. Constr Build Mater 208:697-709

41. Vinter S, Montanes MT, Bednarik V et al (2016) Stabilization/solidification of hot dip galvanizing ash using different binders. J Hazard Mater 320:105-113

42. Wang J, Peng B, Chai LY, Zhang Q, Liu Q (2013) Preparation of electrolytic manganese residueground granulated blastfurnace slag cement. Powder Technol 241:12-18

43. Wang Nan-fang, Sui FZheng-junP Cheng De-xing, Du Bing, Zhou Chang-bo. 2016. Recovery of soluble manganese from electrolyte manganese residue using a combination of ammonia and $\mathrm{CO}_{2}$. Hydrometallurgy.164:288-294

44. Wang Q, Lu R, Chen ZY, Li GQ, Yang YX (2020) CFD and Experimental Investigation of Desulfurization of Rejected Electrolytic Manganese Metal in Electroslag Remelting Process. Metallurgical and Materials Transactions B 51(2):649-663

45. Wang Ya-guang, Shuai G, Mukiza E (2019) Zhang Na. Preparation of non-sintered permeable bricks using electrolytic manganese residue: Environmental and $\mathrm{NH}_{3}-\mathrm{N}$ recovery benefits. J. Hazard. Mater. 378:120768

46. Wang Yang W, Komarneni Sridhar (2014) Yan-xin,. An investigation on the use of electrolytic manganese residue as filler in sulfur concrete. Construction and Building Materials 73: $305-310$

47. Xu LJ, Wang XM, Chen HC, Liu CL (2011) Mn forms and environmental impact of electrolytic manganese residue. Adv Mater Res 183-185:570-574

48. Fei X, Min WTengZ Hou Hao-bo. 2020. Self-solidification/stabilisation of electrolytic manganese residue: Mechanistic insights,Construction and Building Materials. 255,118971

49. Xu Ying-tang (2019) Liu Xiao-ming, Zhang Yu-liang, Tang Bin-wen, Emile Mukiza. Investigation on sulfate activation of electrolytic manganese residue on early activity of blast furnace slag in cementbased cementitious material. Constr. Build. Mater. 229: 116831

50. Yang Chao Lv, Xiaoxin T, Xike W, Yanxin SK (2014) An investigation on the use of electrolytic manganese residue as filler in sulfur concrete. Constr Build Mater 73:305-310

51. Zhang R, Ma X, Shen X, Zhai Y, Zhang T, Ji C, Hong J (2020) Life cycle assessment of electrolytic manganese metal production. Clean Prod 253:119951 
52. Zhang Yu-liang (2019) Liu Xiao-ming, Xu Ying-tang, Tang Bin-wen, Wang Ya-guang, Mukiza Emile. Preparation and characterization of cement treated road base material utilizing electrolytic manganese residue. J. Clean. Prod. 232:980-992

53. Zhang YL, Liu XM, Xu YT, Tang BW, Wang YG, Mukiza E (2019) Synergic effects of electrolytic manganese residue-red mud-carbide slag on the road base strength and durability properties. 220:364-374

54. Zhang Yu-liang (2020) Liu Xiao-ming, Xu Ying-tangu, Tang Bin-wen, Wang Ya-guang. Preparation of road base material by utilizing electrolytic manganese residue based on Si-Al structure: Mechanical properties and $\mathrm{Mn} 2+$ stabilization/solidification characterization,Journal of Hazardous Materials. 390,122188

55. Zhou C, Wang J, Wang N (2013) Treating Electrolytic Manganese Residue With Alkaline Additives For Stabilizing Manganese And Removing Ammonia. Korean J Chem Eng 30(11):2037-2042

56. Zhou Chang-bo, Bing Du, Wang Nan-fang, Chen Zhen (2014) Preparation and strength property of autoclaved bricks from electrolytic manganese residue. J Clean Prod 84:1-8

57. Zhou X, Luo C, Wang J et al (2020) Recycling application ofmodified waste electrolytic manganese anode slag as efficient catalyst for PMS activation,Science of the Total Environment.143120

\section{Figures}

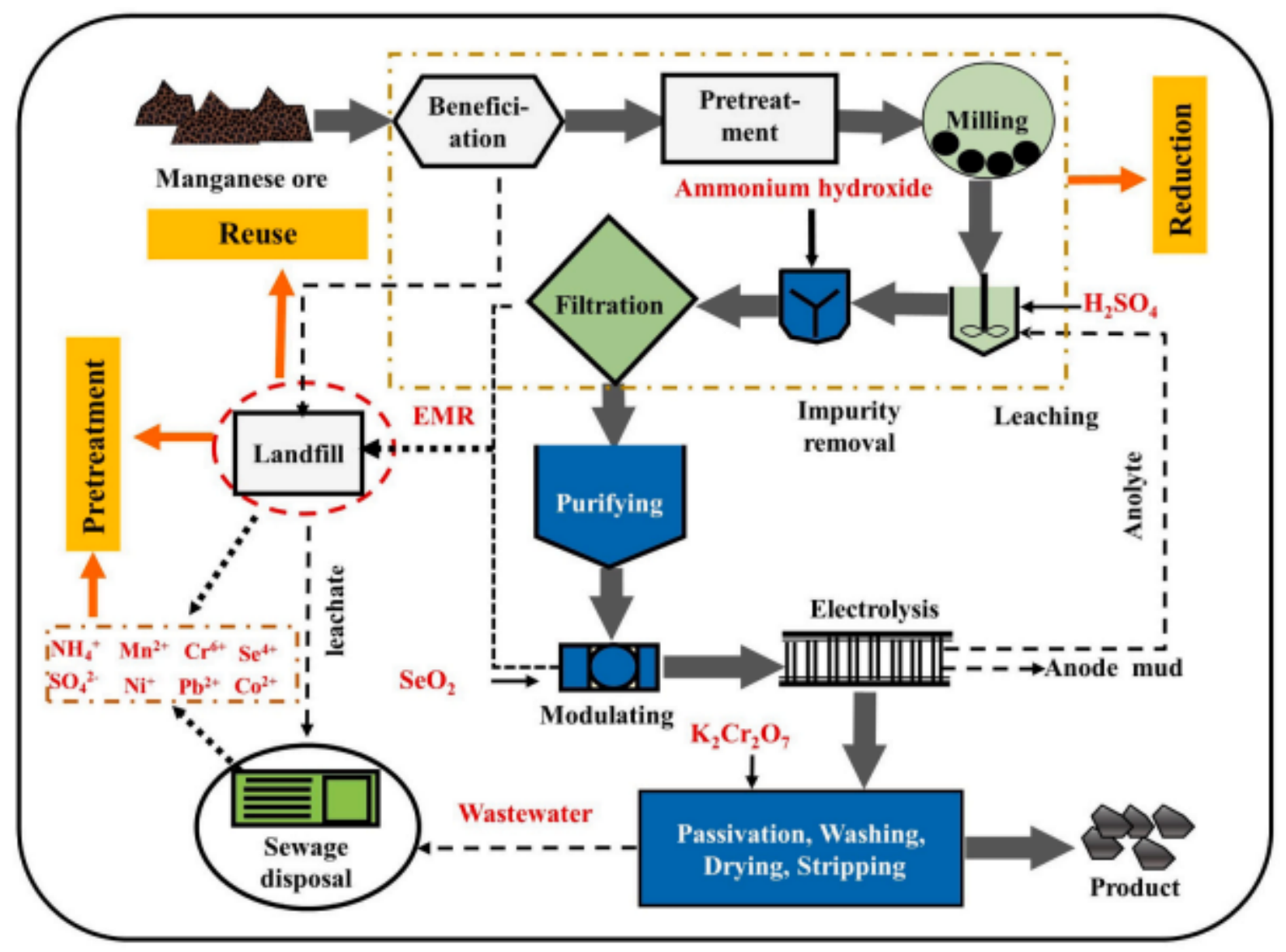


Figure 1

Technical flow chart of EMM(He et al, 2021)

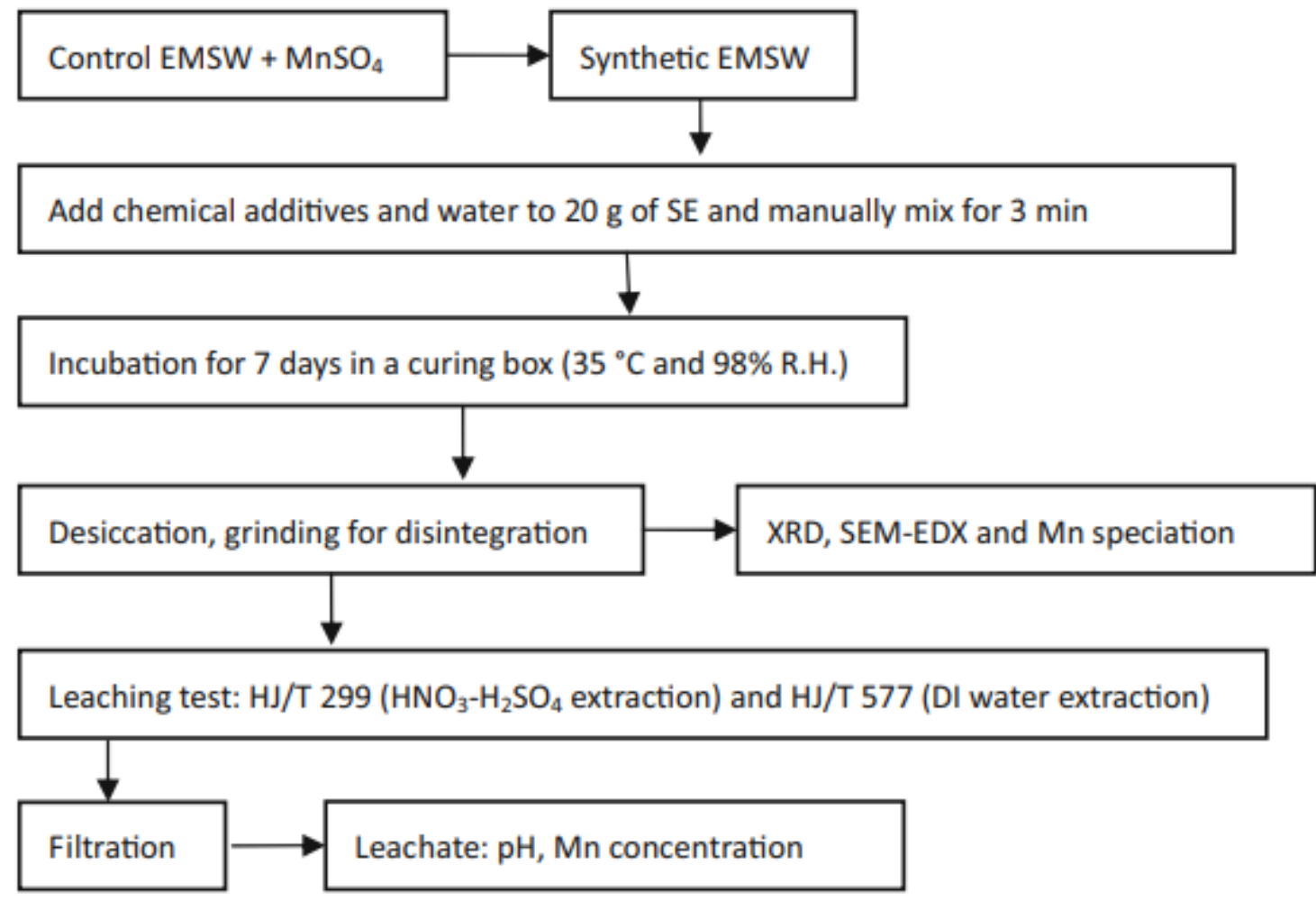

\section{Figure 2}

Experimental methodology for chemical immobilization of soluble Mn(II)(Du et al, 2020) 


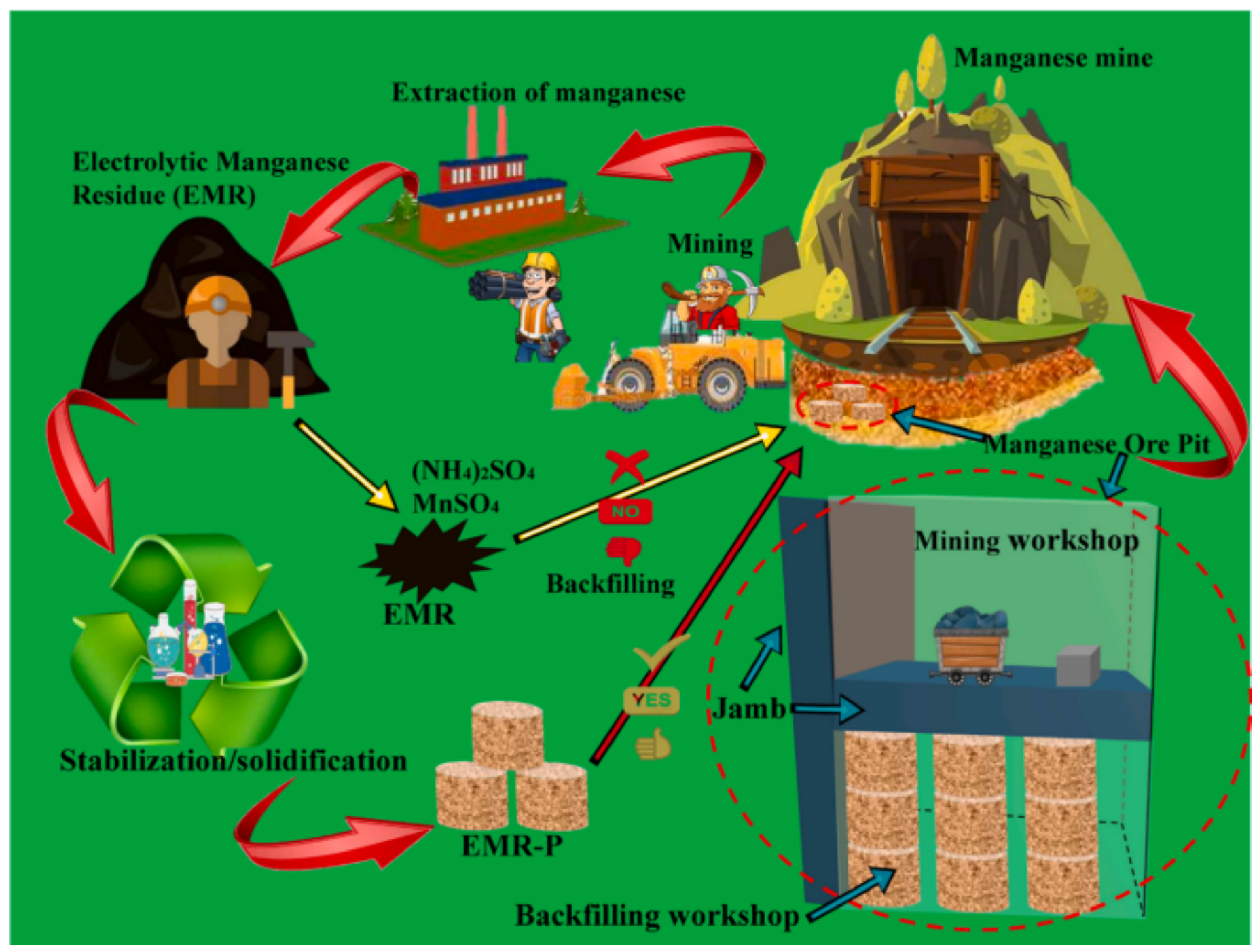

Figure 3

Schematic diagram of backfilling manganese mine pit with EMR-P.P(Lan et al, 2021) 


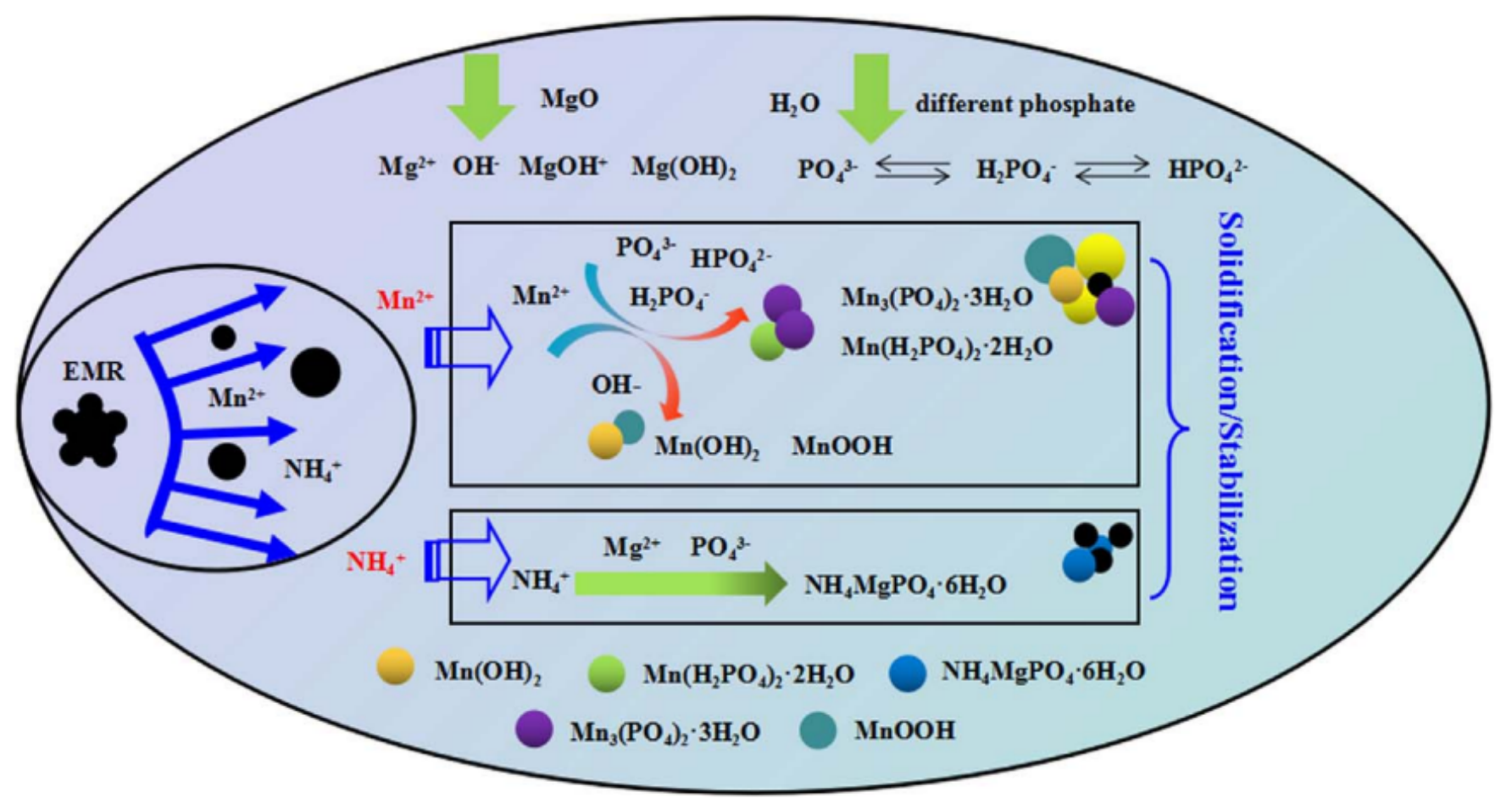

Figure 4

Processes of stabilizing/solidifying Mn2+and NH4+-N(Shu et al, 2018)

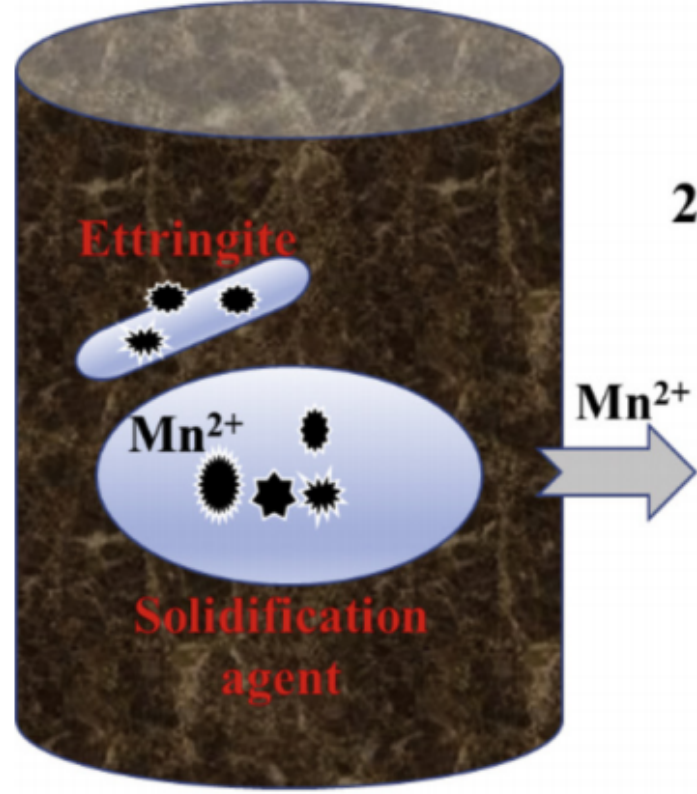

$2 \mathrm{Mn}^{2+}+\mathrm{SiO}_{4}{ }^{4}=\mathrm{Mn}_{2} \mathrm{SiO}_{4}$

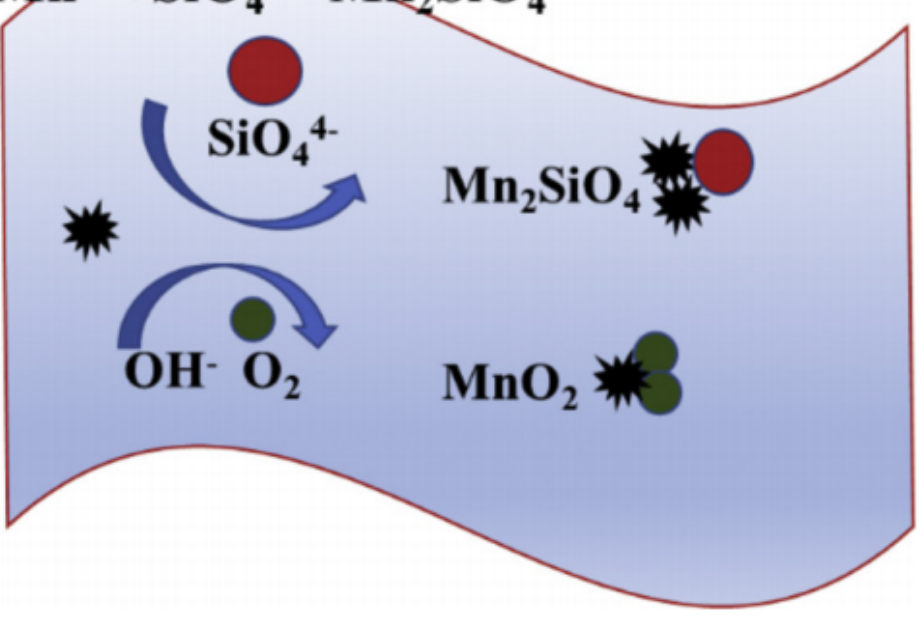

Figure 5

S/S mechanism diagram(Zhang et al, 2020) 


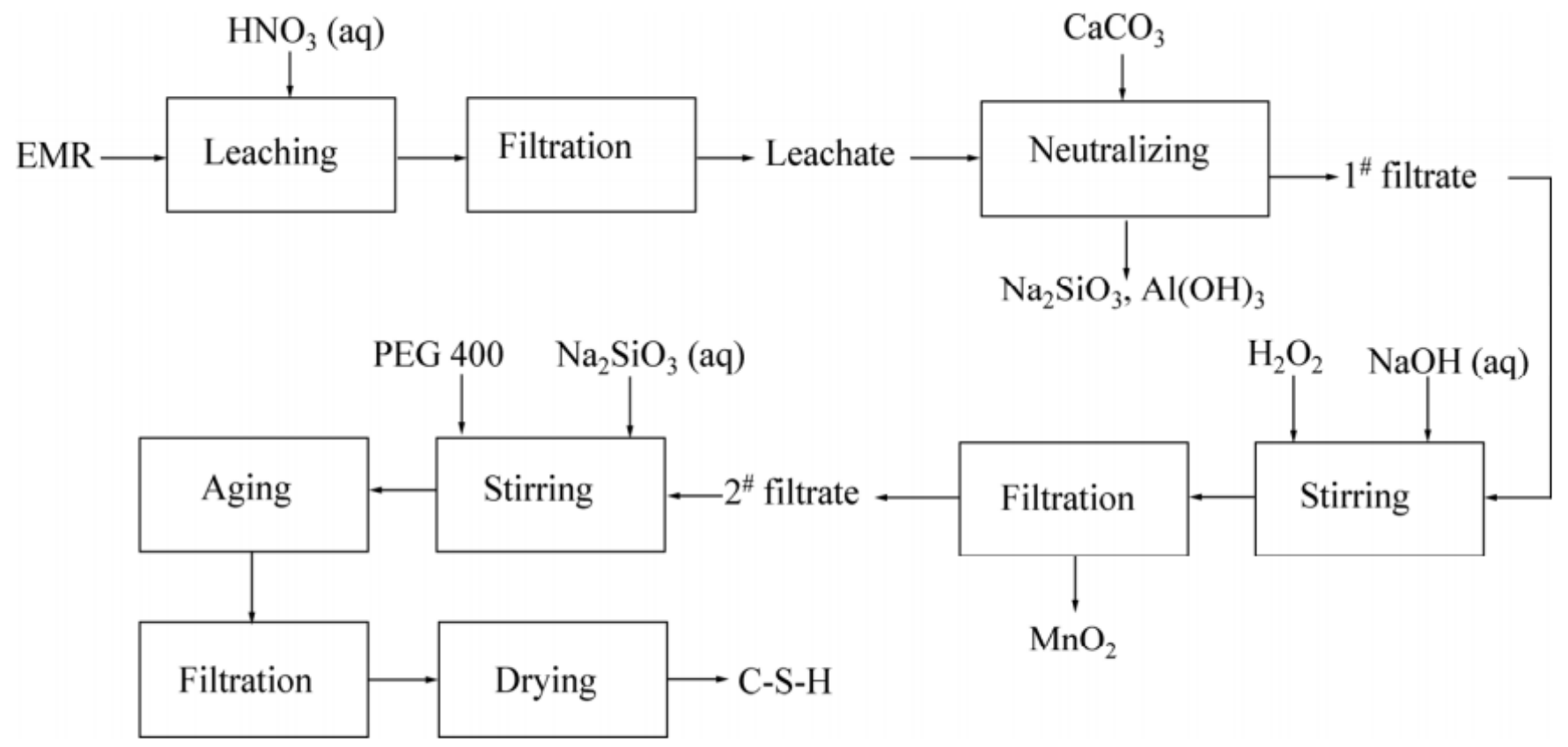

Figure 6

Schematic diagram of Mn recovery route(Li et al, 2015)

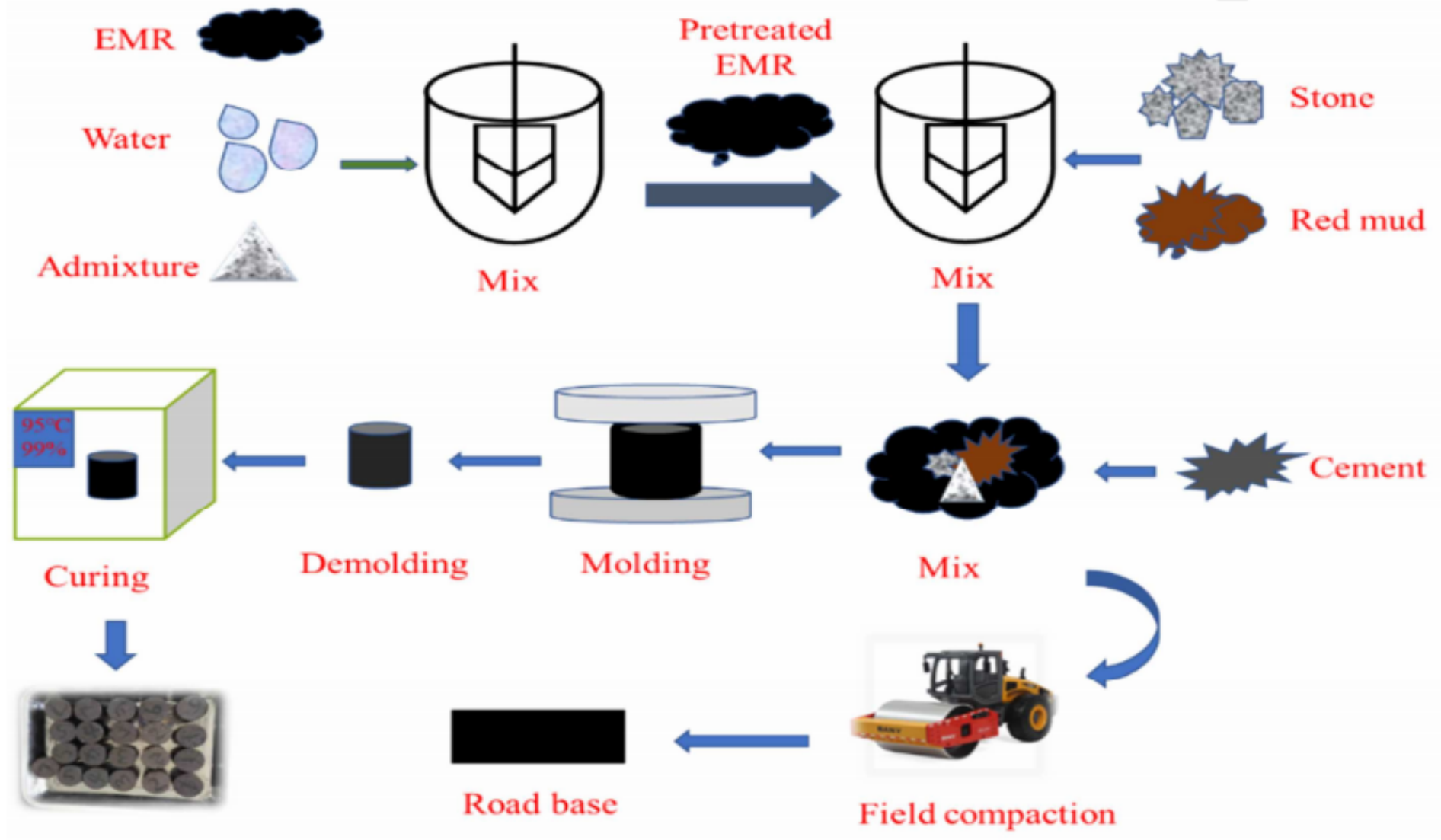

Figure 7 
Preparation Process of Electrolytic Manganese Slag Subgrade Material(Zhang et al, 2019)

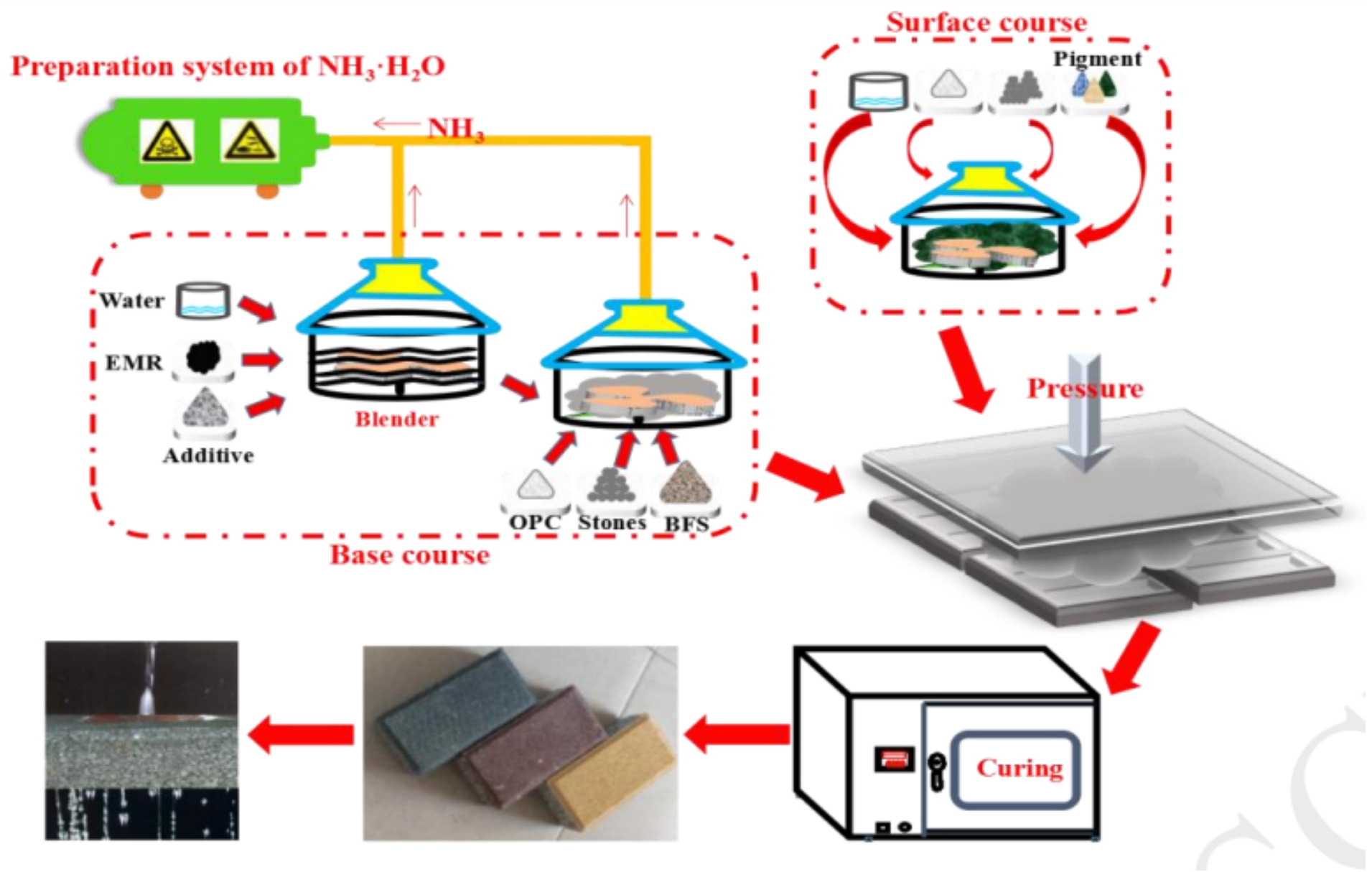

Figure 8

Non-sintered permeable brick preparation process flow chart(Wang et al, 2019) 


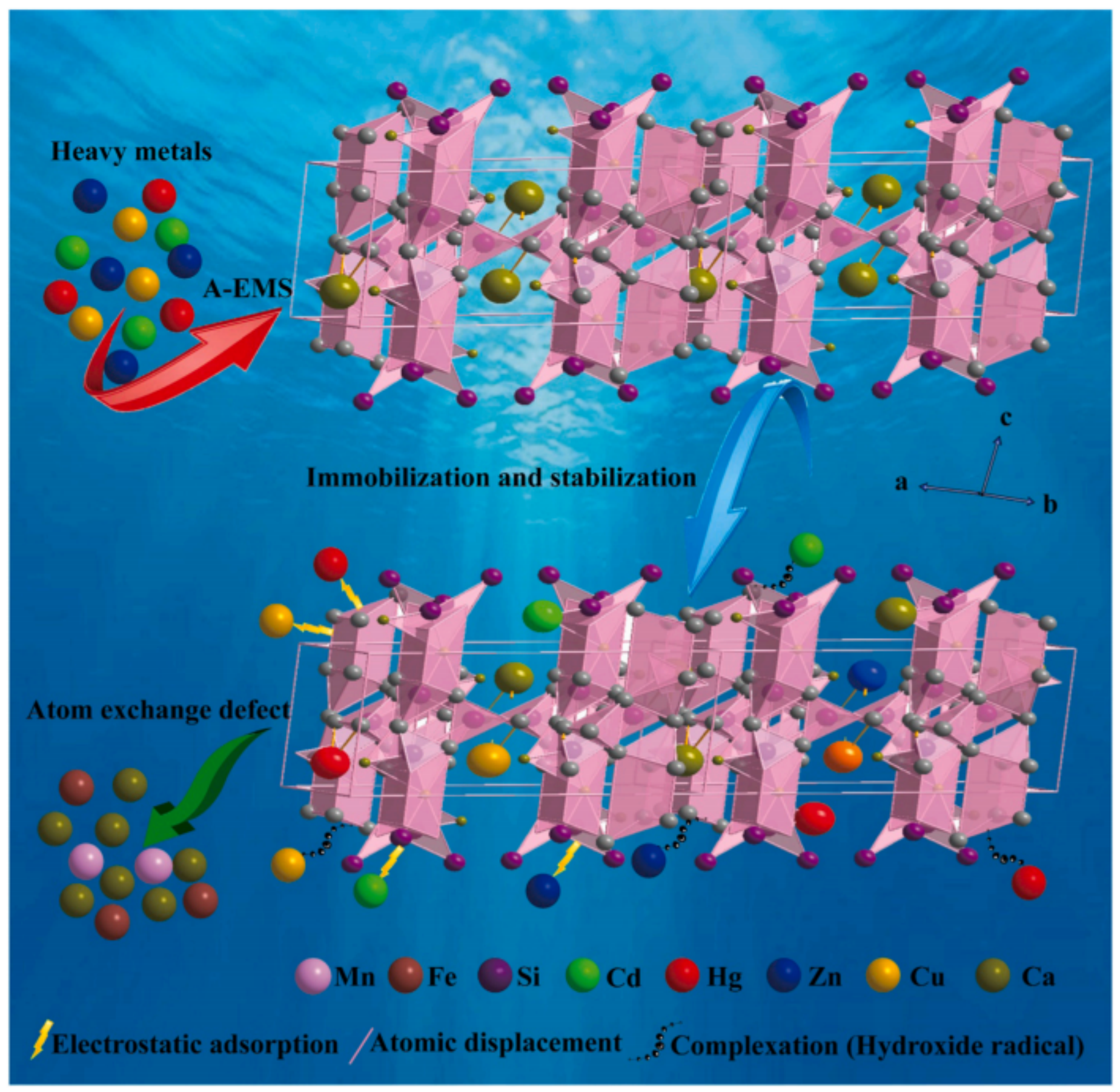

\section{Figure 9}

Mechanism diagram of heavy metals removal and stabilization(Lan et al, 2021) 

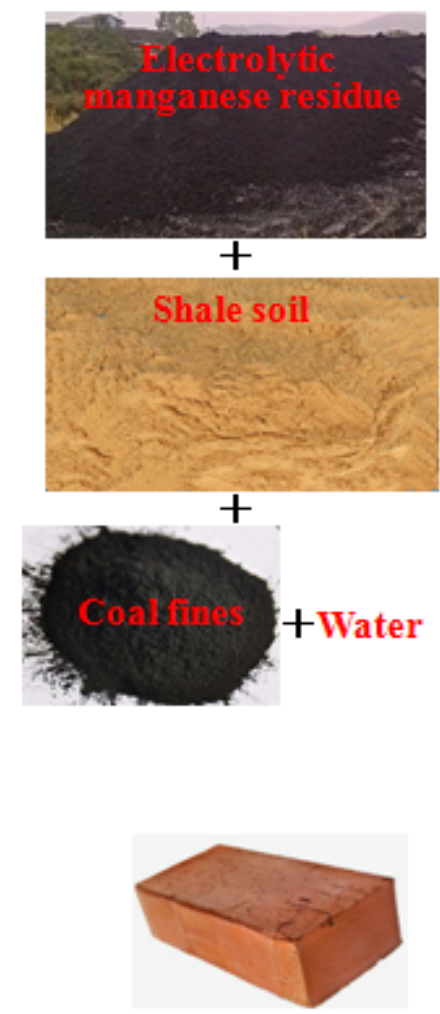

Manganese slag sintered brick
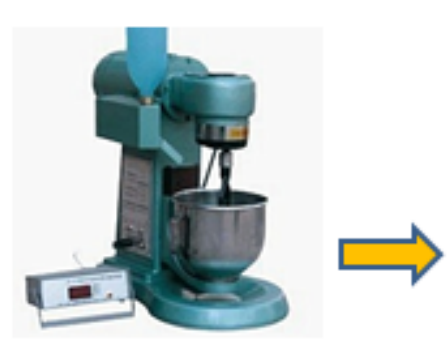

Mixing
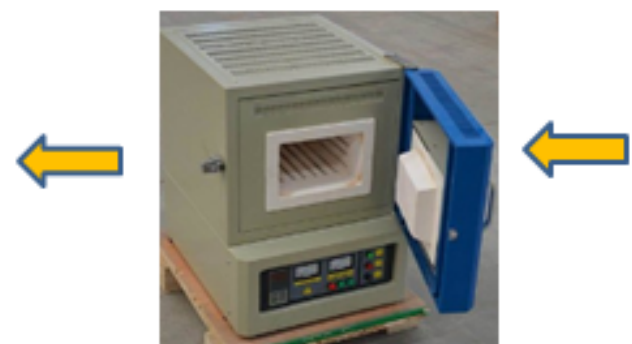

Sintering

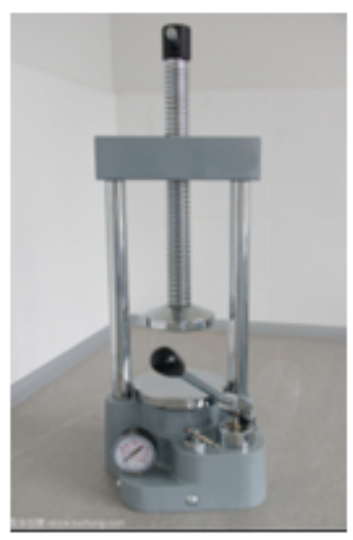

Hydraulic molding
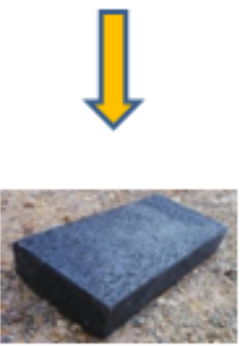

Green body

Figure 10

Specimen preparation flow of EMR sintered brick
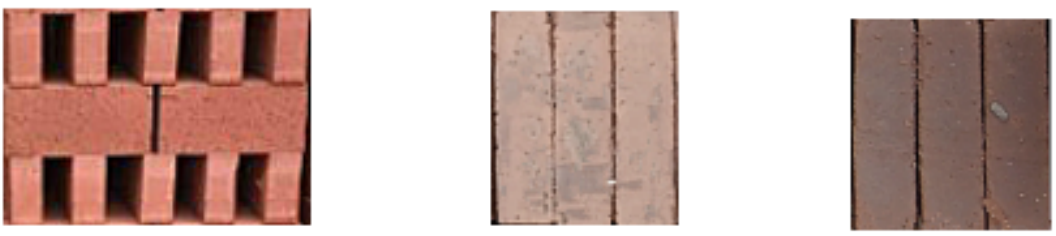

Blank control group $\quad 10 \%$ Manganese slag $20 \%$ Manganese slag brick brick

Figure 11

Appearance of EMR sintered brick 


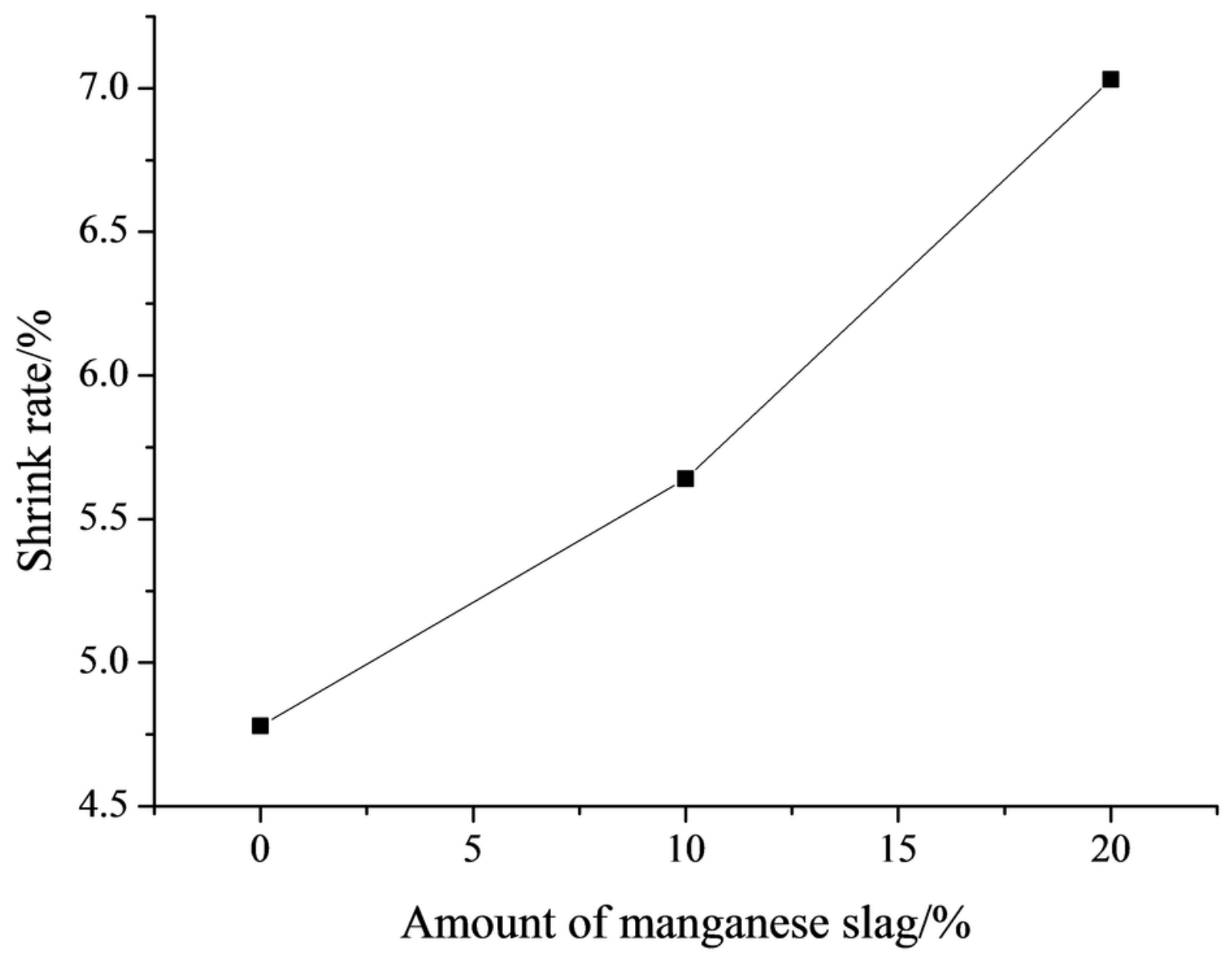

Figure 12

Shrinkage rate of EMR sintered brick 


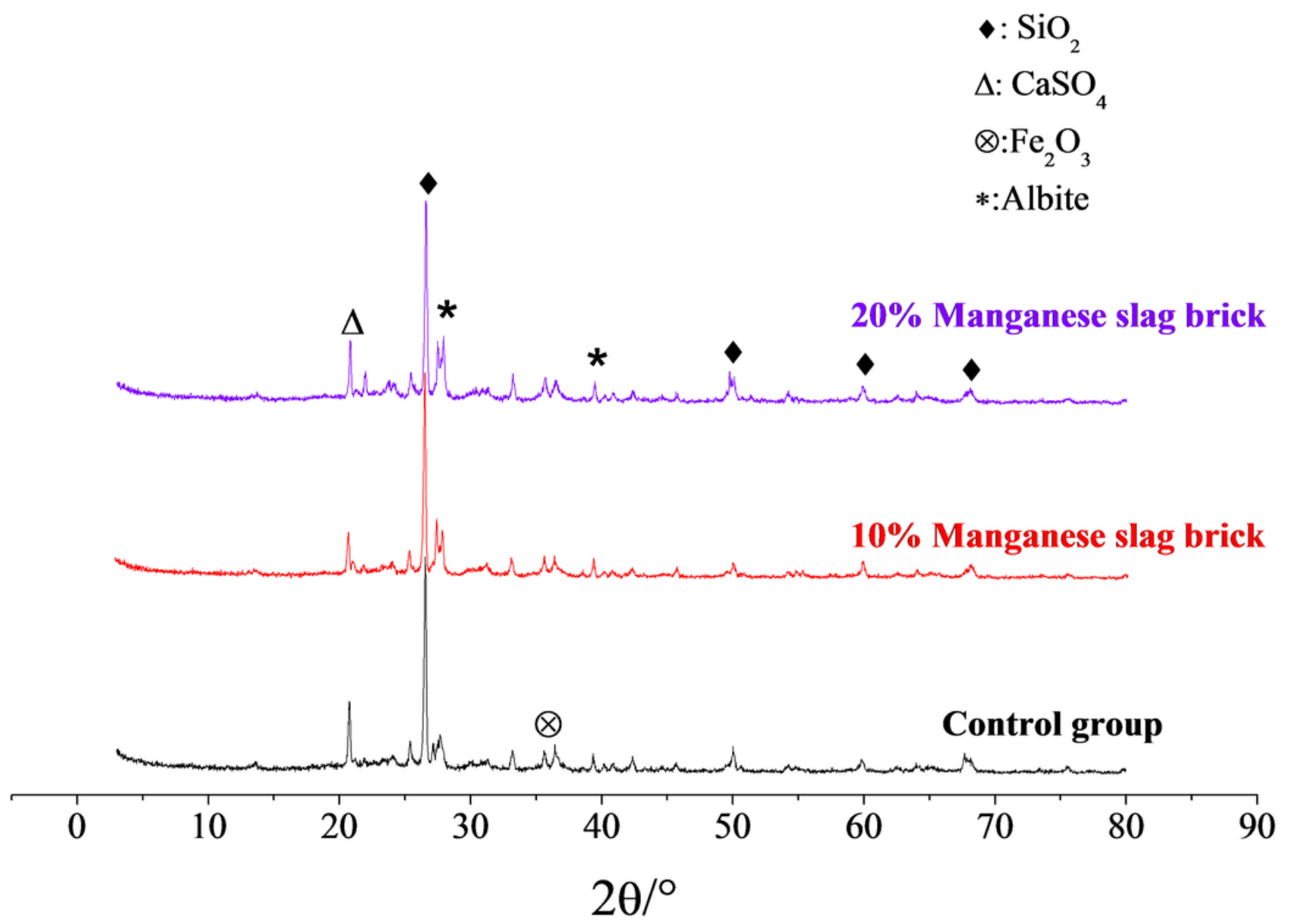

Figure 13

X-ray diffraction pattern of EMR sintered brick 

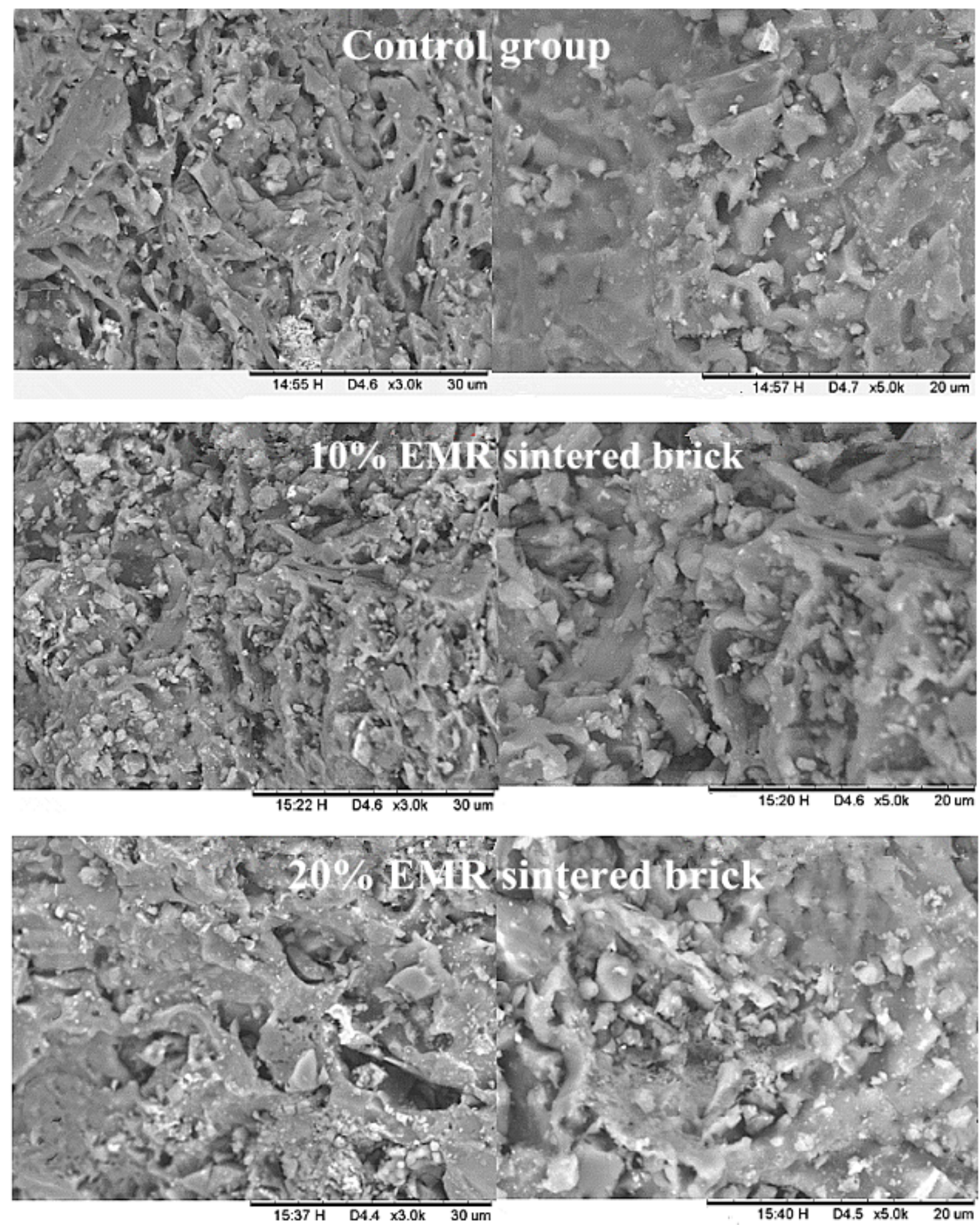

Figure 14

SEM patterns of EMR sintered brick 


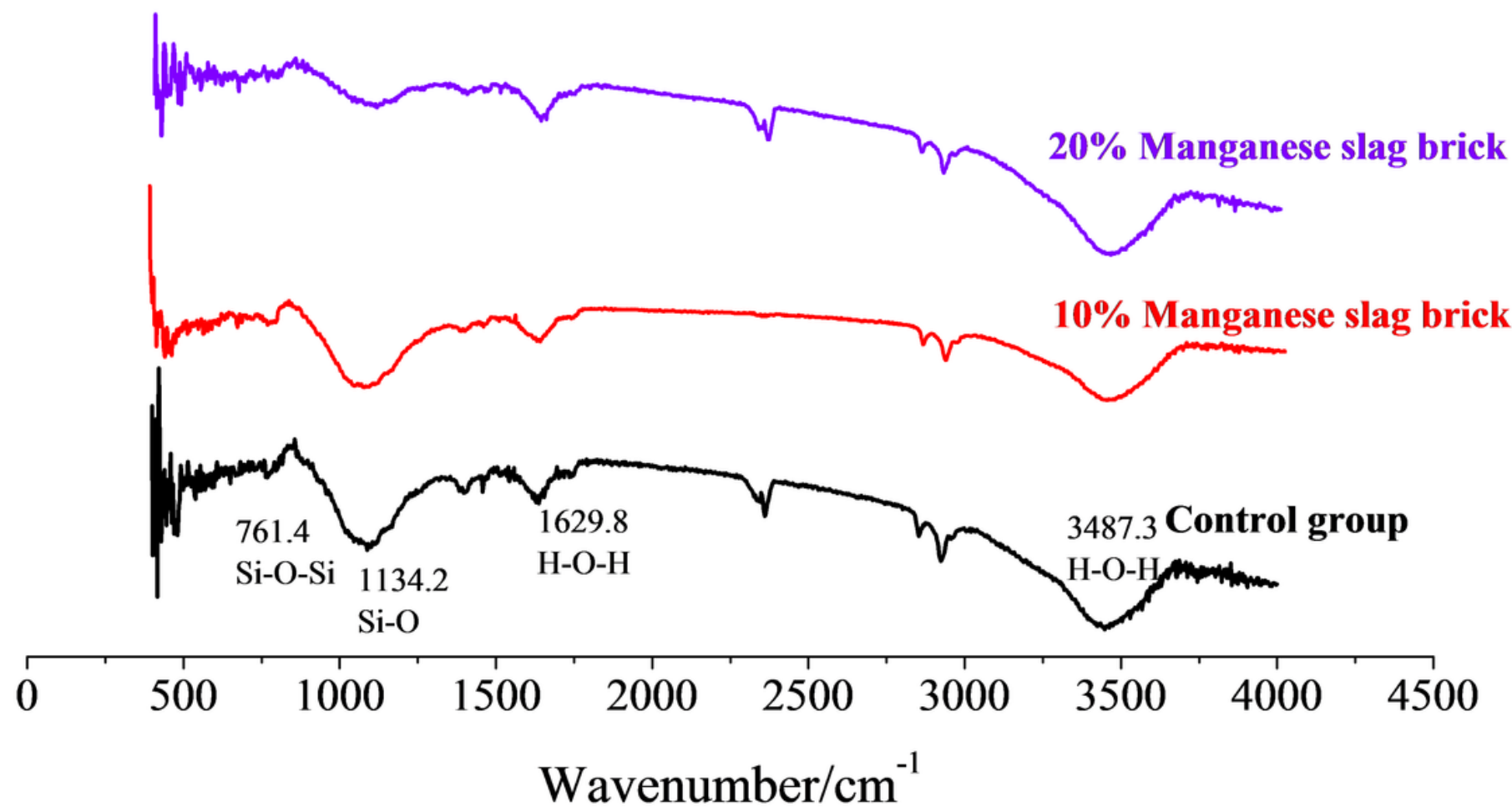

Figure 15

Fourier infrared spectrum pattern of EMR sintered brick 


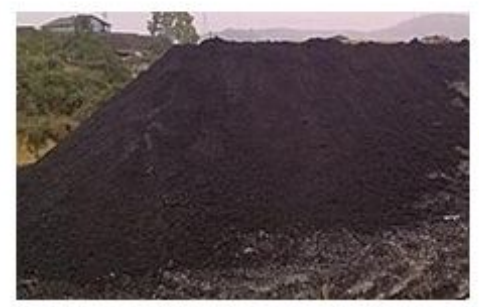

Electrolytic manganese residue

(t)
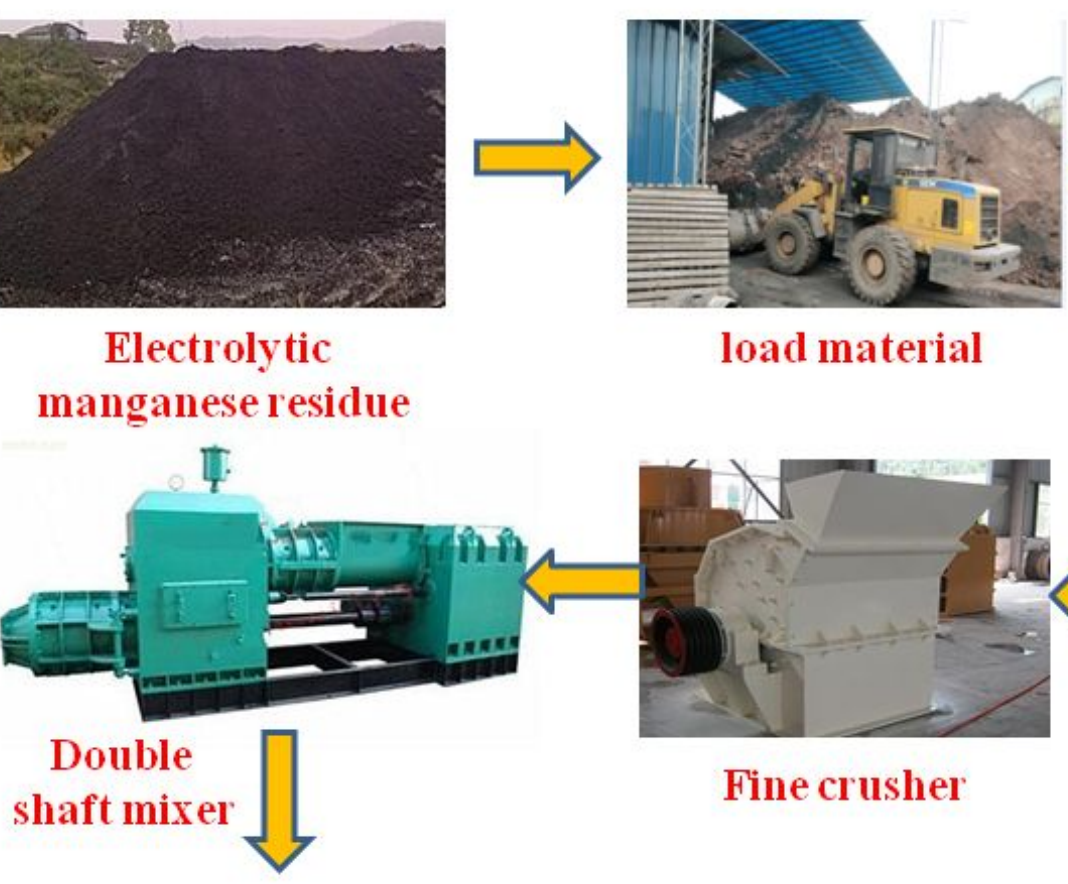

load material

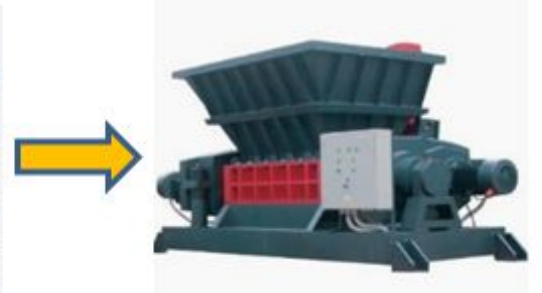

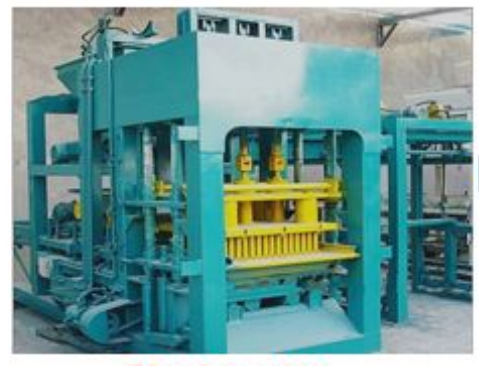

Hydraulic molding machine

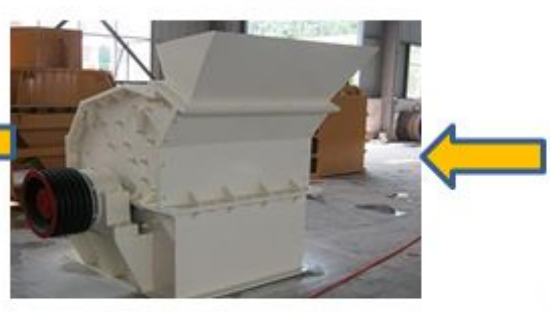

Fine crusher

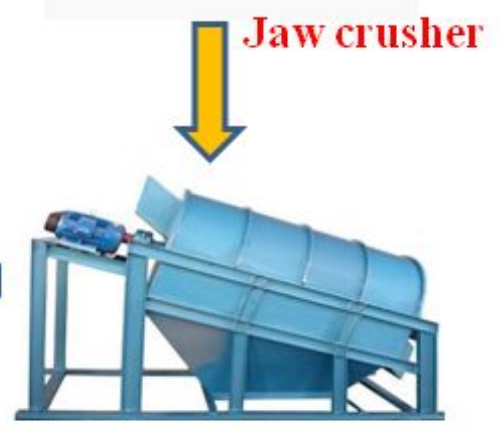

Rotary screen

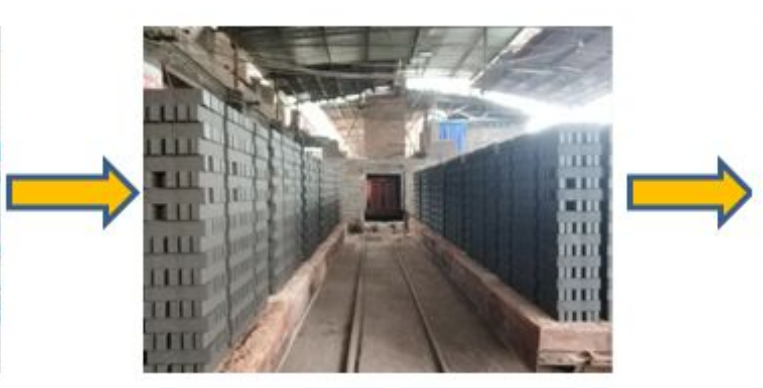

Green brick

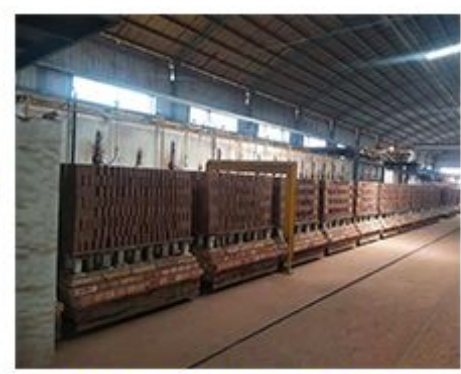

Manganese slag sintered bricks

Figure 16

Practical production flow chart of manganese residue brick 